\title{
Basilar Papilla of the Canary and Zebra Finch: A Quantitative Scanning Electron Microscopical Description
}

\author{
OTTO GLEICH, GEOFFREY A. MANLEY, ALEXANDRA MANDL, \\ AND ROBERT J. DOOLING \\ Institut für Zoologie der Technischen Universität München, 85747 \\ Garching, Germany (O.G., G.A.M., A.M.); Department of Psychology, \\ University of Maryland, College Park, Maryland 20742 (R.J.D.)
}

\begin{abstract}
Morphological parameters of the apical surface of canary and zebra finch basilar papillae were quantitatively evaluated by scanning electron microscopy. The papillar length is $\sim 1.6 \mathrm{~mm}$ in both species. The zebra-finch papilla has a larger number of hair cells and is wider in the apical half of the papilla as compared to the canary. These two small songbird species have the smallest number of hair cells and the smallest papillae of the bird species investigated to date. The orientation of the hair cells is much more homogenous as compared to other species. Also, the discrepancy in the number of stereovilli of neural and abneural hair cells is much larger than in other bird species. A detailed analysis of gradients across the papilla in the canary revealed that anatomical parameters change in the neural half, whereas they remain rather constant in the abneural half of the papilla. There were, however, no obvious borders that separated distinct hair cell populations in either species. 1994 Wiley-Liss, Inc.
\end{abstract}

During the last 20 years, a number of aspects of the physiology and morphology of the avian hearing organ have been studied (review in Manley, '90; Manley and Gleich, '92). After initial qualitative descriptions (review in Smith et al., '85), quantitative evaluations of anatomical parameters of the avian basilar papilla (e.g., Fischer, '92; Fischer et al., '88, '92; Gleich and Manley, '88; Tilney and Saunders, '83; Tilney et al., '87) were carried out. Together with physiological investigations (e.g., Fuchs et al., '88; Manley et al., '85, '89; Sachs et al., '74), including the labelling of characterized single cells (Gleich, '89; Manley et al., '87, '91; Schermuly and Klinke, '90), these anatomical studies contributed to a better understanding of the function and evolution of the avian basilar papilla (Manley and Gleich, '92).

Many quite fundamental questions related to hair cell specializations in birds remain unresolved. The most important of these is the problem of the characterization of hair cell types and their function within the sensory epithelium. Whereas it is clear that tall and short hair cells that are morphologically quite different generally exist on the neural and abneural edge of the epithelium, respectively, there are intergrading types between these extremes and no clearly separated hair cell groups as in mammals. Tall and short hair cells, for which arbitrary morphological criteria have been defined on the light and electron microscopic levels, have been found in every species, whereas so-called intermediate and lenticular hair cell types have not always been identified (Firbas and Müller, '83; Fischer et al., '92; Gleich, '89; Smith et al., '85; Takasaka and Smith, '71; Tanaka and Smith, '78). Previous anatomical data have demonstrated that the distribution of hair cell types within the sensory epithelium is species-specific (Fischer et al., '88; Gleich and Manley, '88; Smith, '85).

Some obvious anatomical specializations have been correlated with specialized functions. For example, the elongation of the barn owl (Tyto alba) cochlea and the lack of morphological gradients in the basal half of its basilar papilla reflect the owl's extended high-frequency hearing range and its special emphasis on the octave between 5 and 10 $\mathrm{kHz}$ (Fischer et al., '88; Köppl et al., '93). In the pigeon (Columba livia), morphological

Address reprint requests to $\mathrm{Dr}$. O. Gleich, who is now at HNO-Klinik, Universität Regensburg, Postfach 93042 Regensburg, Germany. 
o. GLEICH ET AL.

specializations and the increased number of hair cells abneurally at the apex of the cochlea are correlated with the presence of infrasound perception (Gleich and Manley, '88; Kreithen and Quine, '79; Schermuly and Klinke, '90). In species in which a great deal of detailed knowledge exists with regard to anatomy and physiology (starling, chicken, and pigeon), it is obvious that tall hair cells, generally found in the neural part of the papilla, receive a much stronger afferent innervation than abneural hair cells. Recent detailed anatomical studies showed that in the starling (Sturnus vulgaris) and chicken (Gallus gallus), most short hair cells are not afferently innervated at all (Fischer, '92; Fischer et al., '92). Thus these data strengthen the suggestion that tall hair cells have a different function than short hair cells (Manley et al., '89). In most bird species, the height of the hair cells generally reduces toward the basal end on both the neural and abneural sides. Recent data indicate that in the barn owl, whose cochlea processes higher frequencies than those of other species so far investigated (up to $10 \mathrm{kHz}$ ), this size reduction is continued to such an extent that the very base of the cochlea has, according to the classical definition, no tall hair cells at all. In this area, however, the neurally lying cells do have a dense afferent innervation (Köppl et al, '93). Thus we conclude that it is not the shape of a hair cell (tall vs. short) that determines its function, but its position (neural vs. abneural) and innervation. The question thus arises as to whether it is still at all useful to distinguish between hair cell populations using the hair cell shape. In addition, many other anatomical features, and especially the more subtle differences in morphology, cannot as yet be correlated with function. Understanding of these problems requires the collection of detailed, quantitative data on gradients of hair cell morphology both along and across the basilar papilla in representative species of a variety of avian families.

For the present study, two species, the canary (Serinus canarius) and the zebra finch (Taeniopygia [Peophila] guttata), were selected as representatives of small songbirds because their hearing has already been characterized psychophysically (Dooling, '92). In addition, their vocalizations differ substantially from each other and from the vocalizations of the starling, the only other songbird whose cochlea has been studied quantitatively. Using protocols described previously
(Gleich and Manley, '88), we collected data across the papilla, from hair cells located neurally, in the middle and abneurally, in each case for different positions along the length of the papilla. Special emphasis was placed on the comparison of neural and abneural hair cell parameters to characterize the differences between the extreme forms of tall and short hair cells. As differences between neural and abneural hair cells were generally more pronounced in the canaries than in the zebra finches, a number of parameters were quantitatively analyzed in continuous series across the papilla in two cochleae of the canary, in order to characterize the transition from tall to short hair cells more exactly.

\section{MATERIALS AND METHODS}

For the present investigation, we used nine cochleae from a total of five female canaries (Serinus canarius) and three cochleae from two zebra finches (Taeniopygia guttata) of both sexes. The young adult birds were obtained from different local dealers. Although we do not know the exact age of the birds, they were probably $<1$ year old. We also have no record of their previous auditory experience; however, they were probably housed in larger aviaries at the dealers. The methods for the quantitative scanning electron microscopic (SEM) analysis of the basilar papilla surface have already been described in detail (Gleich and Manley, '88) and are only briefly outlined here. The care and use of the animals reported on in this study were according to the requirements of German law.

Birds received a lethal dose of anaesthetics $(30-50 \mathrm{mg} / \mathrm{kg}$ xylacine and $60-100 \mathrm{mg} / \mathrm{kg}$ ketamine), and the base of the cochlea was dissected free. Fixative $(2.5 \%$ glutaraldehyde, $15 \%$ concentrated aqueous picric acid in $0.1 \mathrm{M}$ phosphate buffer) was gently perfused through a small hole in scala tympani and through the ruptured round window membrane for several minutes. The cochlea was then removed from the skull and the surface of the papilla was dissected free of bone and of the tegmentum vasculosum. The specimens were postfixed for 2 days. After several washes in phosphate buffer $(0.1 \mathrm{M}$, $\mathrm{pH} 7.4$ ), the tectorial membrane was removed and the cochleae were osmicated (1\% $\mathrm{OsO}_{4}$ in phosphate buffer) for 1 hour. After three changes in phosphate buffer, the specimens were dehydrated in graded series of alcohol, transferred to liquid carbon dioxide 
for critical-point drying, and sputter-coated according to standard procedures.

Photographs of the papillary surface were taken in the SEM at selected and defined locations. Low-magnification reconstructions of the whole papilla (final magnifications 200800 times) were used to measure gross dimensions (papillar length, papillar width, hair cell numbers, and the number of hair cells across the papilla). Strips across the papilla from neural to abneural and $\sim 50-100 \mu \mathrm{m}$ wide, were reconstructed at high magnification $(2,000-4,000$ times) at 8-10 equally spaced positions along the length of the papilla. These reconstructions were used to determine the orientation of the stereovillar bundle by measuring the angle between the long axis of the bundle and the neural edge of the papilla. The strips across the papilla were each subdivided into areas that were $10 \mu \mathrm{m}$ wide and contained on average seven hair cells (range 2-18). The average hair cell orientation was determined for each of these areas. Iso-orientation contours for the entire papilla were then calculated from these data.

Groups of three to five hair cells on the neural and abneural side, as well as in the middle of the papilla, were selected on the high power prints, or were photographed at magnifications up to 10,000 for further analysis. For these hair cell groups at specific locations on the papilla, we measured a number of parameters: the apical surface area of each hair cell, the area of the hair cell surface covered by the stereovillar bundle, the number of stereovilli per hair cell, and the length of the long and short axis of the bundles as seen perpendicular to the hair cell surface. In addition, the position of the stereovillar bundle on the hair cell was characterized by measuring the distance both between the neural edge of the bundle and the neural border of the hair cell as well as between the abneural edge of the bundle and the abneural border of the hair cell, in both cases perpendicular to the long axis of the stereovillar bundle. Because all of the data were obtained from the same hair cells, we were then able to estimate the average diameter of single stereovilli as the square root of the ratio of the area covered by the bundle and the number of stereovilli.

The ratio of the long and short bundle axes was a measure of the bundle symmetry. The ratio of the abneural bundle distance and the neural bundle distance was used to identify so-called lenticular hair cells. Lenticular hair cells have been described in other avian species (chicken and barn owl, Smith '85). They characteristically have their stereovillar bundle placed excentrically nearer the neural side of the hair cell, and the cuticular plate is present only in the neural part of the hair cell (Smith, '85; Smith et al., '85).

To characterize gradients across the papilla in more detail, a number of parameters were determined for a larger number of hair cells (generally 20-30 of known position across the papilla) at three locations $20 \%$, $50 \%$, and $80 \%$ from the base in high-power reconstructions of $\sim 100-\mu \mathrm{m}$-wide strips in two canary cochleae. These data were analyzed as a function of the distance of each hair cell from the neural border.

The area measurements of hair cells and the surface occupied by the stereovillar bundle were performed using the program HVEM 3D (Laboratory for High Voltage Electron Microscopy, University of Colorado). The dimensions determined from the SEM specimens have not been corrected for the shrinkage that occurred during fixation, dehydration, or critical-point drying.

The data are coded systematically in the figures throughout this report. To increase clarity in the figures that compare canary and zebra finch, we show only smoothed weighted averages of the raw data (Cleveland, '79). The neural position is coded by a continuous line, the middle of the papilla as a dashed line, and abneural as a dotted line. To illustrate the degree of raw data variability, we included the average of each individual obtained at the neural position as open triangles. To identify statistically significant differences between measures obtained from neural and abneural hair cell populations and between canary and zebra finch data, we performed Mann-Whitney U-tests for segments of the basilar papilla with corresponding distances from the base. Differences are only reported in the results section if the statistics indicated a difference in the respective measure with a two-tailed significance level of $5 \%$ or below. The figures that demonstrate in detail the variation across the canary papilla show smoothed weighted averages of the pooled data as well as the raw data obtained from the two canary cochleae analyzed (coded by open squares and open triangles).

\section{RESULTS}

For the morphological comparison, nine cochleae of five canaries and three cochleae of 

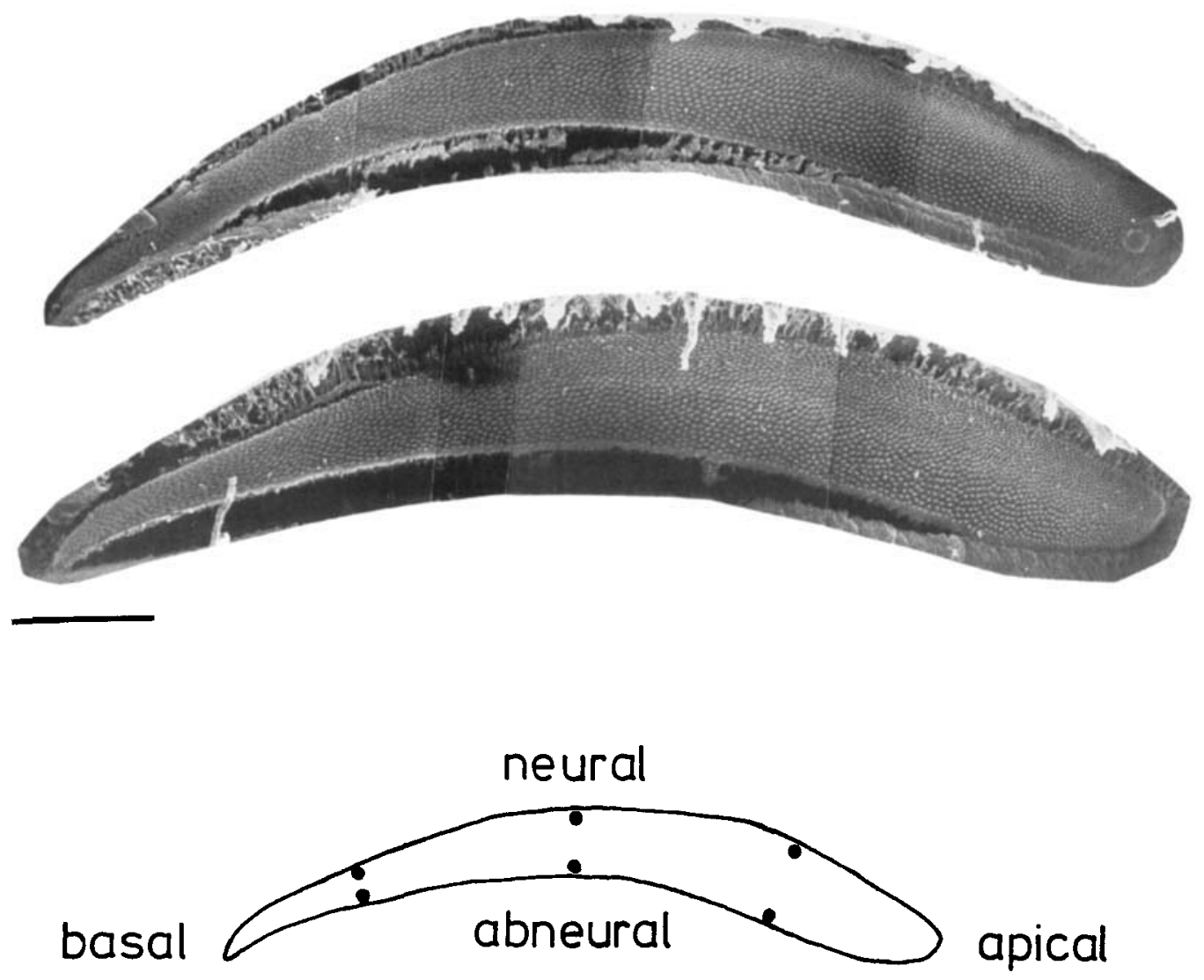

Fig. 1. Serinus canarius and Taeniopygia guttata. Low-power SEM micrographs of the basilar papillae of a canary (top) and a zebra finch (middle). A sketch (bottom) indicates the orientation of the papilla. Dots in the sketch of the papillar outline indicate the positions of high power micrographs illustrated in Figure 3. Bar $=200 \mu \mathrm{m}$.

two zebra finches were available. In the canaries, three papillae of two birds and in zebra finches two papillae of two birds were sufficiently well preserved and free of large artifacts to allow detailed examination. In two canary cochleae from two birds, the parameters were analyzed in detail across the papilla at locations $20 \%, 50 \%$, and $80 \%$ from the base. Measurements of the gross dimensions were performed on all papillae.

The basilar papillae of canary and zebra finch resemble the typical avian form, with a slightly bent papilla that is narrow at the base and becomes wider toward the apex. In Figure 1, typical overviews of a canary (top) and a zebra finch (middle) basilar papilla are shown together with a sketch (bottom) indi- cating the basal and apical as well as neural and abneural directions.

\section{Gross papillar dimensions}

The length of the papillae and the total number of hair cells for the individual cochleae evaluated are listed in Table 1 . The average papillar length determined for the canary was $1,648 \pm 96 \mu \mathrm{m}$, whereas it was $1,625 \pm 37 \mu \mathrm{m}$ in the zebra finch. A MannWhitney U-test indicated no significant difference in papillar length between canaries and zebra finches $(P>0.1)$. In the zebra finch, the variation in total length among papillae was rather small, the difference between the shortest and largest papilla being only $5 \%$ of the average length. In the canary, however, 
the variation was larger, the difference between the shortest and longest papilla being $22 \%$ of the average length. Even the right and left side of individual birds differed by up to $16 \%$ (Table 1 ).

The average number of hair cells was $2,998 \pm 120$ in the canaries and thus significantly smaller than the $3,573 \pm 190$ found in the zebra finches (Mann-Whitney U-test; $P<0.05$ ). In canaries, the variability in hair cell numbers was less than the variability in papillar length. This difference was most obvious in canary \#2 (see Table 1), where the right and left side differed substantially in length $(1,442$ vs. $1,712 \mu \mathrm{m})$, but much less in the number of hair cells $(2,990$ vs. 2,860$)$. Indeed, a larger number of hair cells was found in the shorter papilla. There was no tendency for shorter papillae to contain fewer hair cells. The basilar papillae of canary and zebra finch thus have about the same length, but the number of hair cells was on average $16 \%$ higher in the zebra finch.

The width of the papilla as a function of the distance from the basal end was measured in eight canary (Fig. 2a) and three zebra-finch (Fig. 2b) cochleae. The width increased from the base toward the apex, reached a maximum between $60 \%$ and $80 \%$ and then decreased again in both species. Between $40 \%$ and $80 \%$ from the base, the basilar papilla of the zebra finch was significantly wider than that of the canary (MannWhitney U-test, comparing the width for $10 \%$ segments along the papillae; $P<0.05$ ). Near the base and the apex the width of the basilar papilla was very similar in canaries and zebra finches. The maximum papillar width was on

$T A B L E$ 1. Length of the basilar papilla and the number of hair cells for individual animals ${ }^{1}$

\begin{tabular}{lccl}
\hline Specimen & $\begin{array}{c}\text { Papillar } \\
\text { length }(\mu \mathrm{m})\end{array}$ & $\begin{array}{c}\text { Number of } \\
\text { hair cells }\end{array}$ & Sex \\
\hline Canary 1r & 1,806 & 3,155 & female \\
Canary 11 & 1,605 & 2,895 & female \\
Canary 2r & 1,442 & 2,990 & female \\
Canary 21 & 1,712 & 2,860 & female \\
Canary 31 & 1,664 & 2,926 & female \\
Canary 4r & 1,676 & 3,000 & female \\
Canary 41 & 1,686 & $\mathrm{ND}$ & female \\
Canary 5r & 1,671 & $\mathrm{ND}$ & female \\
Canary 51 & 1,568 & 3,160 & female \\
Zebra finch 1r & $\mathbf{1 , 6 6 0}$ & $\mathbf{3 , 8 4 3}$ & male \\
Zebra finch 2r & 1,573 & 3,425 & female \\
Zebra finch 2l & 1,640 & $\mathbf{3 , 4 5 0}$ & female \\
\hline
\end{tabular}

${ }^{1}$ In two canaries ( 1 and 2 ) and in one zebra finch (2) both the right and left cochleae were fully analyzed.

$\mathrm{ND}=$ not determined . average $142 \mu \mathrm{m}$ (range 130-155 $\mu \mathrm{m}$ ) in the canary and $175 \mu \mathrm{m}$ (range $170-180 \mu \mathrm{m}$ ) in the zebra finch.

The number of hair cells across the papilla as a function of the position along the papilla (Fig. 2c,d) followed the width of the papilla. The number of hair cells across the papilla was significantly larger in zebra finches as compared to canaries between $60 \%$ and $80 \%$ from the basal end (Mann-Whitney U-test, comparing the number of hair cells across the papilla for $10 \%$ segments along the papillae; $P<0.05$ ). For more basal and apical portions of the papilla, the difference between canaries and zebra finches was not significant.

\section{Apical hair cell surface area}

Typical high-power pictures of canary hair cells are illustrated in Figure 3, together with sketches that illustrate a number of the measures performed. The top row shows neural and the bottom row abneural hair cells. The examples in the left column are $20 \%$ from the base, the middle column is $50 \%$, and the right column $80 \%$ from the base. In the following, the gradients along and across the papilla that could be deduced from these prints are quantitatively analysed. The sketch shows the outline of a hair cell and its stereovillar bundle and indicates some of the measured parameters.

The apical surface area of the hair cells showed systematic trends in both canary and zebra finch (Fig. 4). In both species, neurally lying hair cells had systematically smaller surface areas along the papilla as compared to abneural hair cells. In contrast to the canary (Fig. 4a), the apical hair cell surface area showed no systematic variation along the papilla for the middle and abneural positions in the zebra finch (Fig. 4b). Hair cell surface area of abneural hair cells was significantly smaller in zebra finch as compared to the canary between $30 \%$ and $70 \%$ from the base.

The variation of the hair cell surface area across the papillar width is shown in detail for a basal (20\%), middle $(50 \%)$, and apical (80\%) position in two canary specimens (Fig. 5). The values at the most neural, middle, and abneural positions were consistent with the description obtained from the other three canary specimens and shown in Figure 4 . At the base (Fig. 5a), the hair cell surface area showed a small maximum in the middle of 

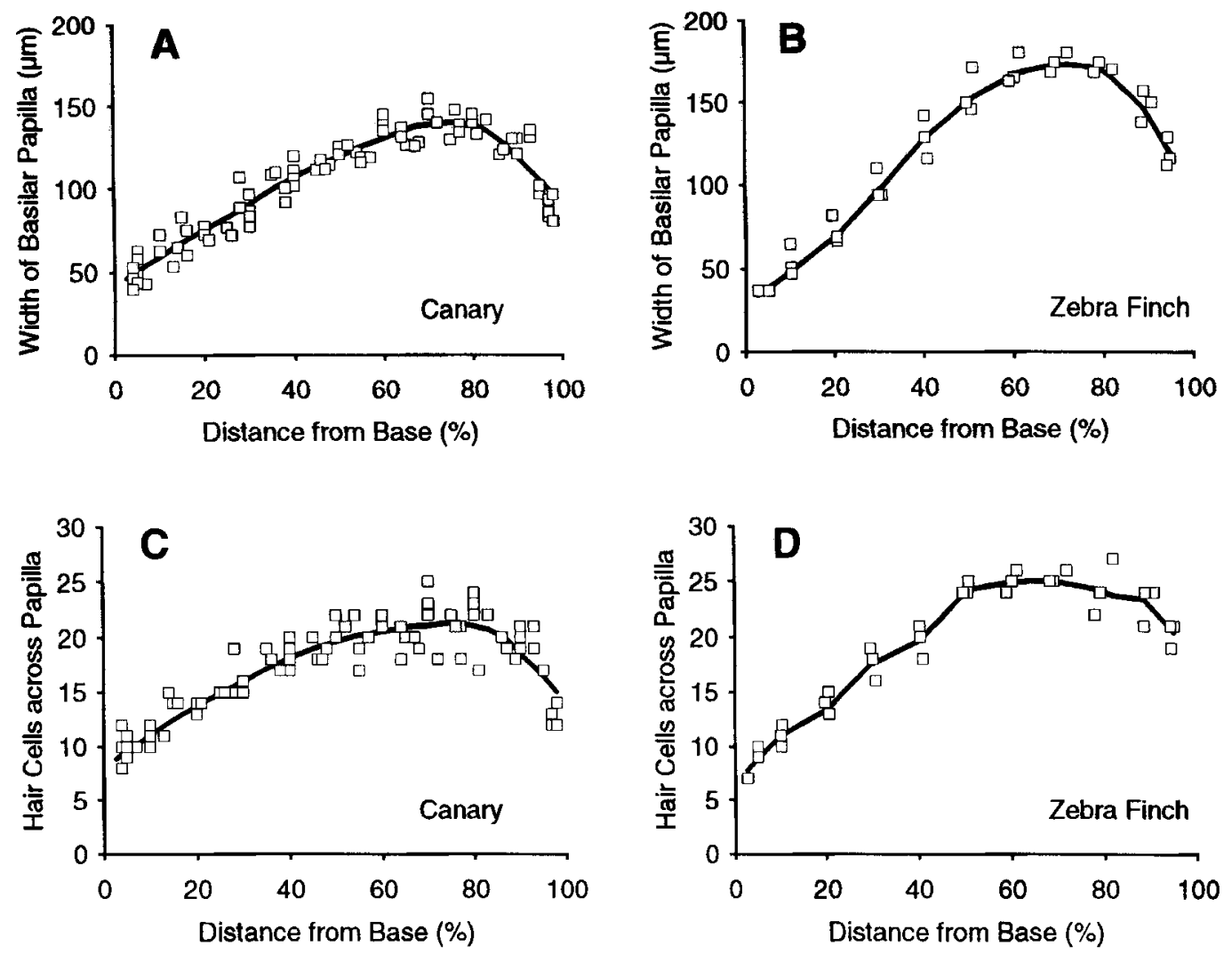

Fig. 2. Serinus canarius and Taeniopygia guttata. The width of the basilar papilla (A and B) and the number of hair cells counted across the papilla (C and $\mathbf{D}$ ) as a function of the distance from the basal end. Results are shown for eight canaries ( $A$ and $C$ ) and three zebra finches (B and D). Shown are the smoothed weighted averages (continuous lines) and the raw data (open squares).

the papilla. At the $50 \%$ position (Fig. $5 \mathrm{~b}$ ), hair cell surface area varied little in the neural fifth of the papilla but increased rather abruptly to almost $60 \mu \mathrm{m}^{2}$ and remained near this value in the abneural two thirds of the papilla. At the apex (Fig. 5c), the hair cell surface area increased almost continuously across the abneural three quarters of the papilla.

\section{Analysis of the stereovillar bundle}

Area of the stereovillar bundle

As the micromechanical properties of the stereovillar bundle influence the responses of the hair cell, we analyzed the stereovillar bundles in some detail. The area of the apical hair cell surface that is covered by the stereovillar bundle as a function of the hair cell's position on the papilla is shown in Figure 6 . In both species, the surface area occupied by the bundle decreased from $\sim 15 \mu \mathrm{m}^{2}$ at the base to $5 \mu \mathrm{m}^{2}$ at the apex. Between $20 \%$ and $80 \%$ from the base in the canary and between $40 \%$ and $90 \%$ in the zebra finch, the area occupied by the bundle was significantly larger in neural than in abneural hair cells. The hair cells in the middle of the papilla between the neural and abneural position tended to have intermediate surface areas in the canary (Fig. 6a), whereas they appeared more similar to neural hair cells in the zebra finch (Fig. 6b).

The details of the variation of bundle area across the papilla at the three positions in the canary (Fig. 7) were consistent with the data of Figure 6a. At all three positions studied, 



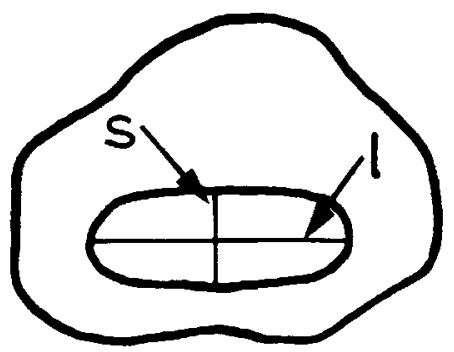

Fig. 3. Serinus canarius. High-power SEM micrographs of canary hair cells. The top row shows neural and the bottom row shows abneural hair cells. The left column gives examples at $20 \%$ from the base; the middle and right column show hair cells from $50 \%$ and $80 \%$ from the base, respectively. These positions are indicated by the dots in the sketch of Figure 1. The sketches at the bottom

the bundle area decreased from the neural towards the abneural edge of the papilla.

\section{Number of stereovilli}

The distribution of the number of stereovilli in individual hair cell bundles was very similar in canary and zebra finch (Fig. 8). In both species, the number of stereovilli was significantly larger on neural hair cells as compared to hair cells in abneural positions. This difference was largest in the basal half of the papilla, where the number of stereovilli of neural hair cells remained almost constant at around 200 in both species over more

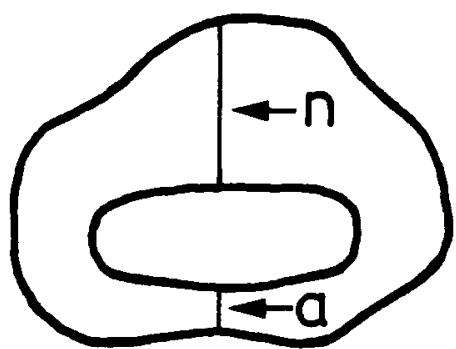

illustrate a number of measures performed on the hair cells. The outlines of the hair cell and the bundle illustrate the area measurements. The left sketch indicates the long (1) and short (s) axis of the stereovillar bundle. The right sketch illustrates the distance between the bundle and the abneural (a) and the neural (n) hair-cell border. $B a r=10 \mu \mathrm{m}$.

than half of the papillar length. In the apical half of the papilla, the number of stereovilli on neural hair cells decreased from 200 to below 100 at the apex. The number of stereovilli on hair cells in the middle of the papilla was, in both species, only slightly larger than that of abneural hair cells and decreased in both groups from 150 or 180 at the base to $\sim 60$ at the apex.

The details of the variation of stereovillar number across the canary papilla (Fig. 9) were consistent with the results of Figure 8. The number of stereovilli decreased at all positions from neural to abneural. 

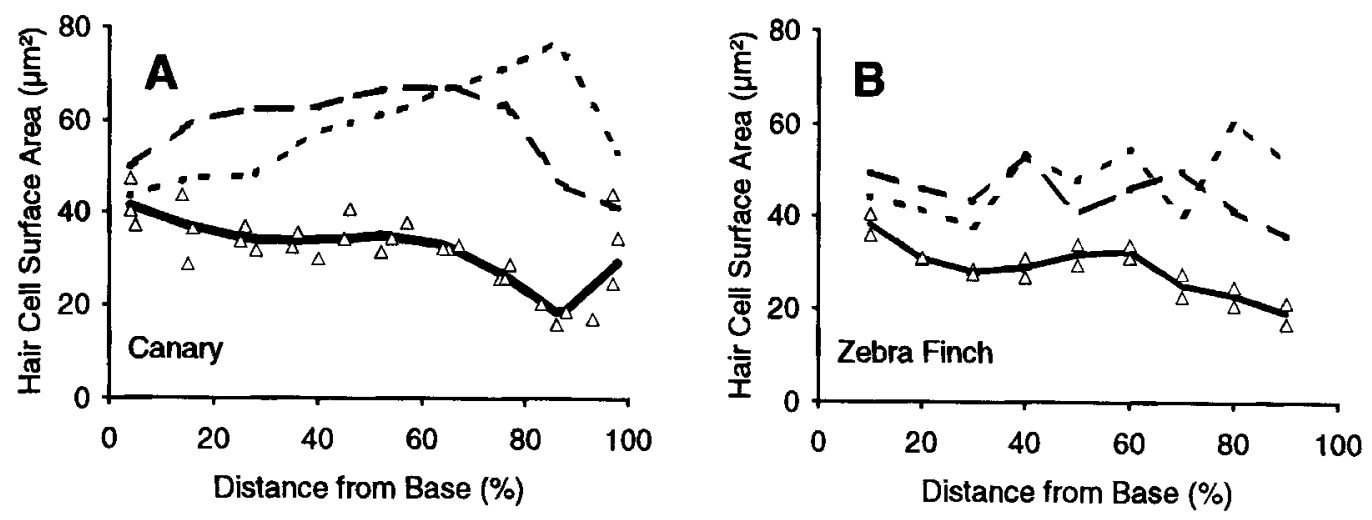

Fig. 4. Serinus canarius and Taeniopygia guttata. The hair cell surface area as a function of the distance from the base. Averaged data are shown for three canary (A) and two zebra finch (B) specimens. The smoothed weighted average for the functions of neural (continuous lines), middle (dashed lines), and abneural (dotted lines) hair cells are given together with the raw data obtained from neural hair cells.

\section{Diameter of single stereovilli}

The difference between neural and abneural hair cells with respect to the number of stereovilli (Figs. 8, 9) was much more pronounced than that for the area occupied by the stereovillar bundle (Figs. 6, 7). Thus the diameters of stereovilli of neural hair cells must be smaller than those of abneural hair cells. As the stereovillar numbers and the bundle areas were determined for the same hair cells, the average area occupied by a single villus was estimated by taking the square root of this area as an estimate of the average stereovillar diameter (Gleich and Manley, '88). The diameter of stereovilli was systematically and at most positions significantly smaller in neural hair cells $(\sim 0.25$ $\mu \mathrm{m})$ than in those from middle or abneural positions on the papilla $(\sim 0.28 \mu \mathrm{m})$ in both species. The stereovillar diameter did not change much along the length of the papilla in these specimens. A detailed analysis of mean stereovillus diameter across the canary papilla confirmed the finding that stereovilli were on average slightly thinner on neural as compared to abneural hair cells.

\section{Dimensions of the stereovillar bundle}

The long and short axes of the stereovillar bundle in the plane of the papillar surface are two measures that characterize the shape of the bundles. Figure 3 indicates in the sketch of a hair cell (left) the parameters known as the bundle long (l) and short axis (s). In both species, there was a tendency for the long axis of the bundle to decrease from $\sim 8.5 \mu \mathrm{m}$ at the base to $3 \mu \mathrm{m}$ at the apex (Fig. 10a,b). Bundles on neural hair cells were systematically longer than those of abneural hair cells except at $10 \%$ from the base in both species, the difference between positions being larger in the canary than in the zebra finch (Fig. $10 a, b)$. The short axis of the stereovillar bundles showed only small variations along and across the papilla in both species (Fig. $10 \mathrm{c}, \mathrm{d})$.

The detailed characterization of the variation of the hair cell bundle axes across the canary papilla (Fig. 11) confirmed the small neural-abneural variations shown in Figure 10. The bundle long axis decreased in length gradually from neural to abneural at all three positions investigated $(20 \%, 50 \%$, and $80 \%$ from the base). The bundle short axis showed little variation across the papilla at the positions $20 \%$ and $50 \%$ from the base, with the exception that the most neural hair cells had slightly longer bundle short axes. In the most apical position investigated (Fig. 11f), the bundle short axis showed little variation across the papilla.

\section{Symmetry of the stereovillar bundle}

The ratio of the long and short bundle axes is a measure of the shape of the bundles (Fig. 12). High values indicate elongated bundles, whereas low values characterize rounded stereovillar bundles. In both species, these ratios were larger at the base, but the patterns differed significantly at most positions along 

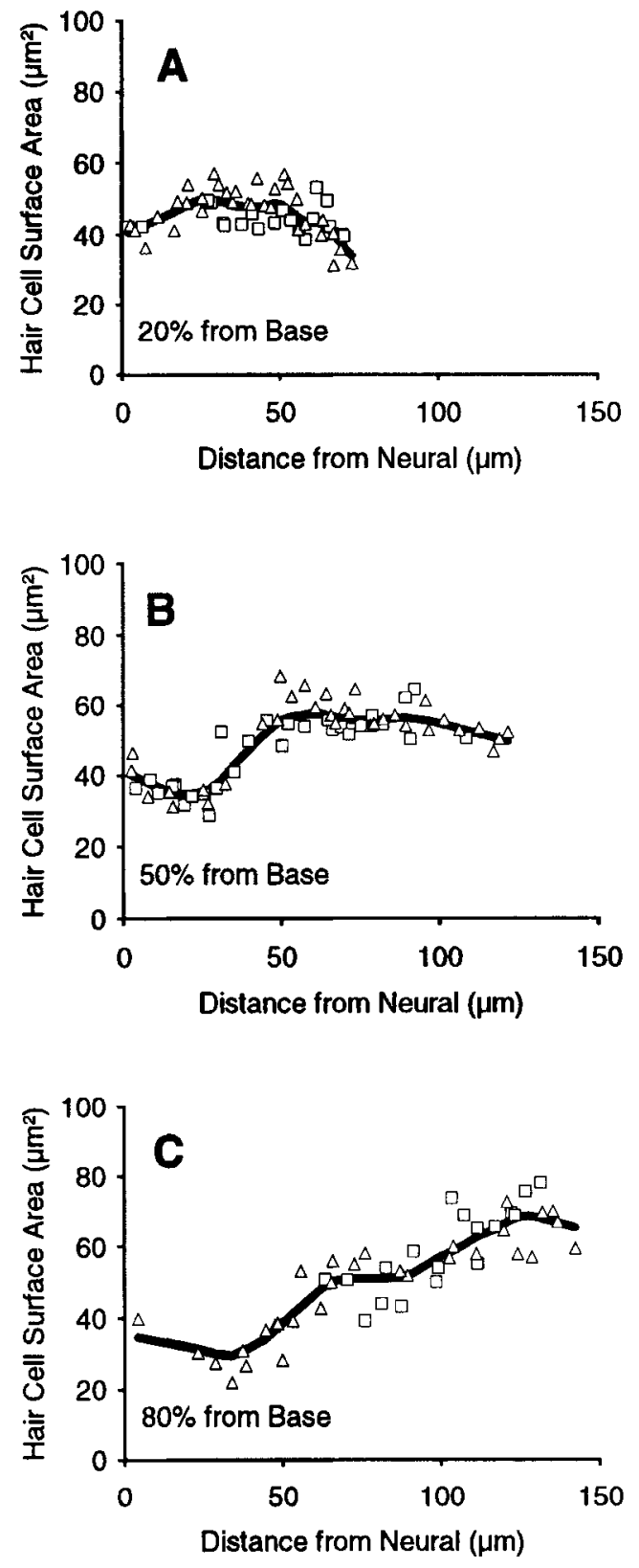

Fig. 5. Serinus canarius. The hair cell surface area determined across the papilla in two canary specimens at (A) $20 \%$ (B) $50 \%$, and (C) $80 \%$ from the basal end. Open squares and triangles code data from two different individuals. The heavy line shows the smoothed, weighted averages through the data. the papilla between canary and zebra finch. In the canary (Fig. 12a), the change of the bundle shape was small in the basal $60 \%$ of the papilla at all positions across the papilla. For abneural canary hair cells, the elongation of the bundles decreased gradually from the $60 \%$ position toward the apex, whereas in neural hair cells, the bundle shape ratio decreased more apically, resulting in significantly more elongated bundles of neural hair cells in the apical $40 \%$ of the papilla. In the zebra-finch cochlea (Fig. 12b), neural hair cell bundles were significantly more elongated than those of abneural hair cells between $20 \%$ and $40 \%$ from the base. The bundle elongation in the zebra finch decreased over the basal third of the papilla and then remained rather constant toward the apex.

The detailed analysis of the variation of bundle shape across the canary papilla revealed that it did not vary systematically across the width at the basal and middle positions. In the apical position, however, the elongation of hair bundles decreased conspicuously in the neural third of the papilla but remained rather constant in the abneural two thirds.

Position of the stereovillar bundle on the hair cell

The right sketch in Figure 3 indicates the distance between the neural (n) and abneural (a) edge of the bundle and the borders of the hair cell. These measures are shown quantitatively along the basilar papilla in Figure 13. In both species, the patterns shown for neural and abneural cells were clearly and significantly different along the whole papilla. The bundles of neural hair cells were consistently located very close $(1 \mu \mathrm{m})$ to the neural border of the hair cell (Fig. 13a,b). Only at the most apical position in the canary did this distance increase slightly. In contrast, for hair cells from the middle and abneural position in both species, the distance between the bundle and the neural hair cell border increased from $\sim 2 \mu \mathrm{m}$ at the base to $5-6 \mu \mathrm{m}$ near the apical end. The distance between the bundle and the abneural border of the hair cell (Fig. $13 \mathrm{c}, \mathrm{d})$ showed no differences between hair cells from neural or abneural positions along the length of the papilla in the canary. In the zebra finch, however, the distance of the bundle to the abneural hair cell border was significantly larger for neural hair cells between $40 \%$ and $70 \%$ from the base as compared to abneural hair cells. In the canary, 

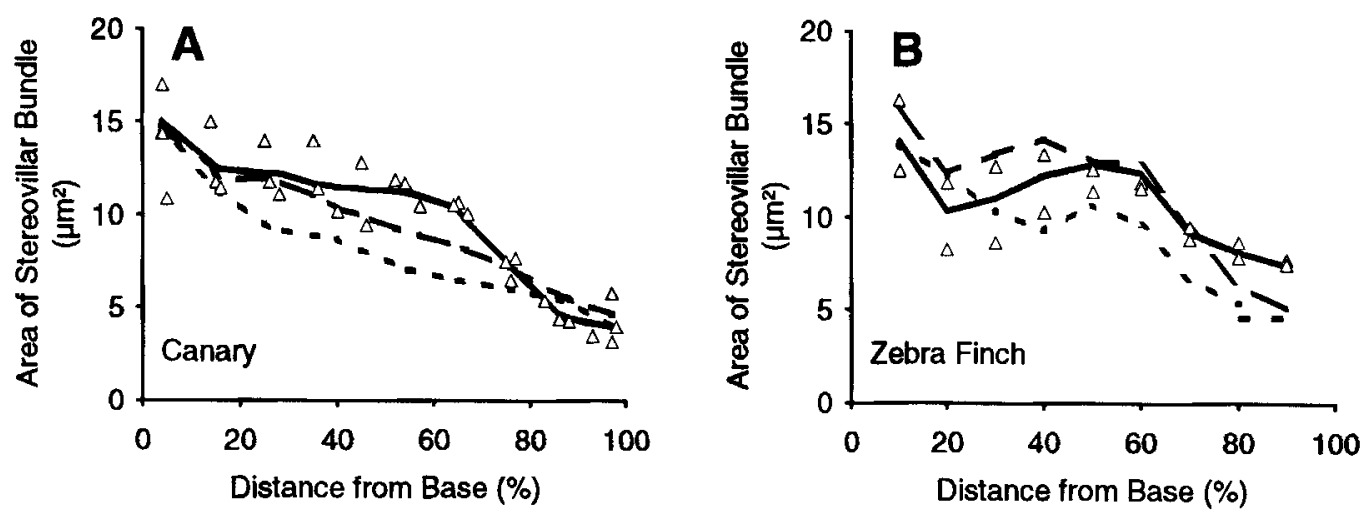

Fig. 6. Serinus canarius and Taeniopygia guttata. The area of the hair cell surface occupied by the stereovillar bundle as a function of the distance from the base for neural (continuous lines), middle (dashed lines), and abneural (dotted lines) hair cells. Open triangles show raw data obtained at the neural position. Averaged data are shown for three canary (A) and two zebra finch (B) specimens.

the abneural bundle distance for all hair cells decreased continuously from the base to the apex (from $2-2.5 \mu \mathrm{m}$ at the base to $\sim 1 \mu \mathrm{m}$ at $65 \%$ ).

The detailed analysis of the bundle distance to the neural and abneural cell border in the canary (Fig. 14) showed complex variations across the papilla. The distance to the neural cell border (Fig. 14a,c,e) increased at all three positions from neural toward the middle of the papilla, reached a plateau, and decreased then slightly toward the abneural edge. The bundle distance to the abneural cell border (Fig. 14b,d,f) was very variable at the most basal position, leading to a complex fluctuating pattern in the smoothed average between the neural and abneural side of the papilla (Fig. 14b). At 50\% from the base, it showed a low maximum in the neural half of the papilla (Fig. 14d). At $80 \%$ from the base, this parameter was rather constant across the papilla (Fig. 14f).

Although the SEM does not allow investigation of cuticular plates, potential lenticular hair cells (see introductory section) could be identified by finding those cells for which the ratio of abneural to neural bundle distance to the hair-cell border is above unity (i.e., the bundle is located on the neural side of the hair cell). The ratio of abneural to neural bundle distance along the papilla (Fig. 15) differed significantly between neural and $\mathbf{a b}$ neural positions in the papillae of both species. In the canary (Fig. 13a), neural hair cells in the basal two-thirds of the papilla had a ratio greater than 1 and were thus potential lenticular hair cells. In the most basal position of the canary papilla, some hair cells in the middle and on the abneural side of the papilla had their stereovillar bundle also placed excentrically on the neural side of the hair cell. In all other hair cells from the canary, the stereovillar bundle was located on the abneural hair cell side. In the zebra finch (Fig. 15b), the maximum of eccentric bundle placement toward the neural side of the hair cell was in neural hair cells at $\sim 40 \%$ from the base. In this species, hair cells in the middle and abneural side of the papilla did not qualify as potential lenticular hair cells due to the abneural location of their stereovillar bundle on the hair cell.

The detailed analysis of the variation of hair bundle location across the canary papilla (Fig. 16) showed that this parameter differed at the three locations tested along the papilla, confirming the data presented in Figure 15. Thus in the canary, potential lenticular hair cells were very common in the most basal $10-20 \%$ of the papilla and restricted to the neural portion of the papilla between $20 \%$ and $60 \%$ from the base. At more apical locations, there were hardly any potential lenticular hair cells.

\section{Orientation of the stereovillar bundles}

The left sketch in Figure 3 indicates the long axis (l) of the stereovillar bundle. We measured the angle between the bundle long axis and the neural edge of the basilar papilla to determine the orientation of the stereovillar bundles. As in other bird species investi- 

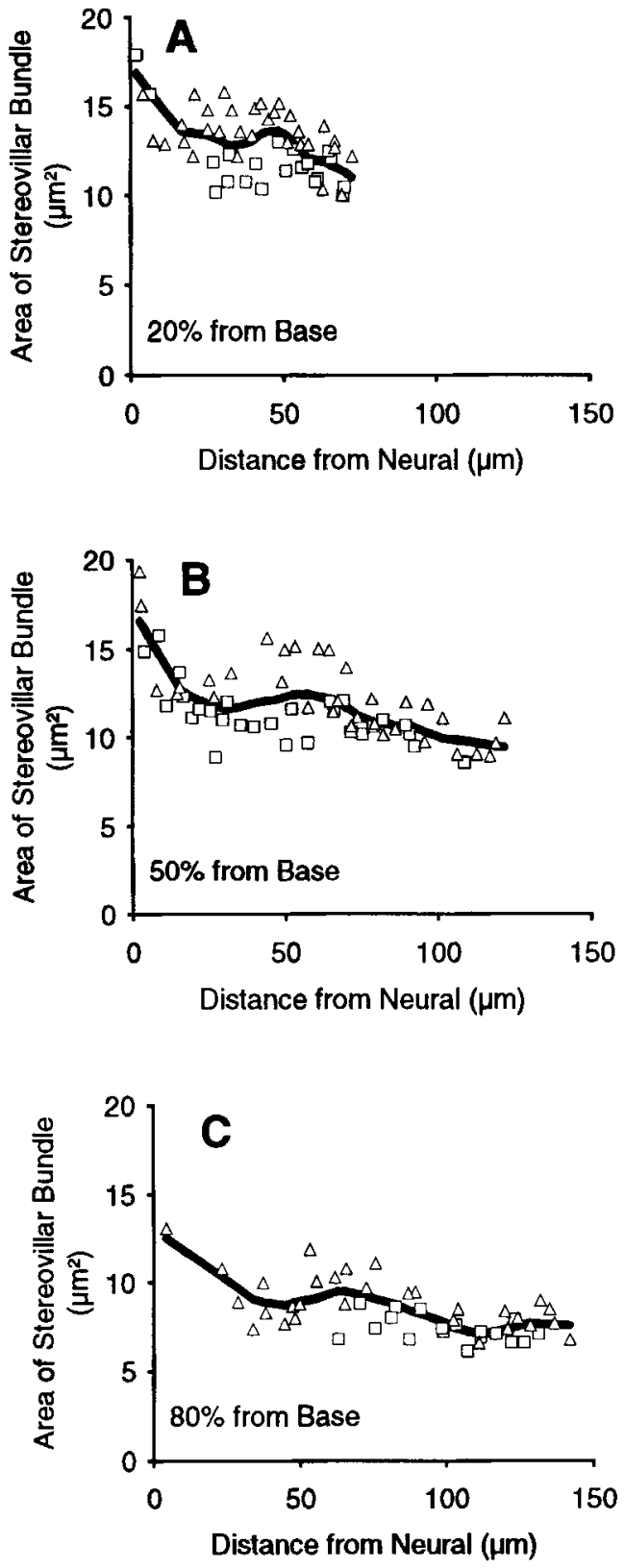

Fig. 7. Serinus canarius. The area occupied by the stereovillar bundle was determined in two canary specimens across the papilla at (A) $20 \%$, (B) $50 \%$, and (C) $80 \%$ from the basal end. Open squares and triangles code data from two different individuals. The heavy line shows the smoothed weighted average through the data. gated (Fischer et al., '88; Gleich and Manley, '88; Tilney et al., '87), the orientation of stereovillar bundles in canary and zebra finch showed a systematic variation over the surface of the basilar papilla, as shown in isoorientation contours for two canary (Fig. $17 \mathrm{a}, \mathrm{b})$ and two zebra finch (Fig. 17c,d) cochleae. In both species, the long axes of the stereovillar bundles on the neural and abneural side of the papilla were oriented parallel to the neural edge of the papilla (indicated by low values for orientation angles) so that if shearing forces are perpendicular to the papillar long axis, these bundles would be maximally stimulated (Hudspeth and Jacobs, '79). Hair bundles toward the middle of the papilla (i.e., between the neural and abneural edge) were rotated such that their most excitatory direction is pointing more toward the apex (indicated by larger values for orientation angles). The maximum bundle rotation increased systematically from the basal toward the apical end of the papilla, reaching between $30^{\circ}$ and $40^{\circ}$ at the apex of the canary and zebra finch papilla (Fig. 17). In the basal two-thirds of the papilla, the rotation of hair bundles was generally small $\left(<20^{\circ}\right)$ in both species.

\section{DISCUSSION}

The present study illustrates that the basilar papillae of canary and zebra finch are very similar in many respects. However, significant species-specific anatomical differences exist at the SEM level between the basilar papillae of these two small songbird species. This is consistent with other avian data in that the cochleae of the avian species investigated to date (see, e.g., review in Manley, '90; Manley and Gleich, '92) are each morphologically unique. We are not aware of any studies that show sex- and age-related variations of cochlear hair cell morphology in adult birds. Ryals and Westbrook ('88) demonstrated that in quail hair cell numbers did not change as a function of age between 3 months and 6 years. In addition, it has been shown that birds have the capacity to restore a normally appearing basilar papilla even after severe hair cell loss (Cotanche and Corwin, '91). This capacity for regeneration is even present in senescent birds (Ryals and Westbrook, '90). In our specimens, we did not see any of the pathologies typical for drug- or noise-induced trauma to the cochlea. Thus we can exclude the possibility that gross hair cell pathologies affected our measurements. We cannot, however, exclude very subtle ef- 

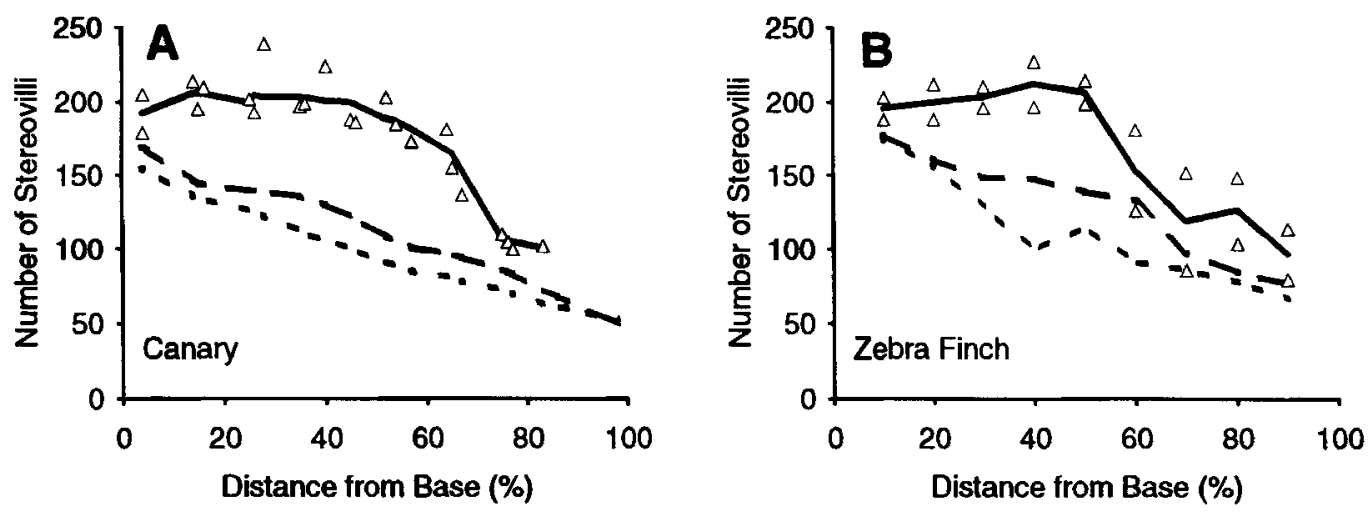

Fig. 8. Serinus canarius and Taeniopygia guttata. The number of stereovilli of a hair cell as a function of the distance from the base for neural (continuous lines), middle (dashed lines), and abneural (dotted lines) hair cells. Open triangles show raw data obtained at the neural position. Data are shown for (A) three canary and (B) two zebra finch specimens.

fects of the previous auditory experience on hair cell morphology in our specimens. However, considering the ability to repair major hair cell loss in birds and the fact that we investigated young adult birds, we believe that differences in prior auditory experience did not seriously affect our data.

\section{Gradients across the papilla: Are there separate hair cell groups?}

Some investigations of anatomical gradients have studied whether changes may occur not only along but also across the papilla and have looked at neural, abneural, and central positions (Fischer et al., '88; Gleich and Manley, '88; Tilney and Saunders, '83). However, in view of the different criteria used to delineate different hair cell types, we felt it necessary to investigate the morphological gradients continuously across the papilla. Such an analysis should allow the discrimination of distinct hair cell groups that can be identified as tall, intermediate, short, or lenticular hair cells according to systematic differences in the anatomical parameters.

The results of Figures 5, 7, 9, 11, 14, and 16 demonstrate that each anatomical feature changed in a complicated fashion across the papilla and that each parameter changed in a unique way. This point is emphasized in Figure 18, where some of the gradients across the papilla (hair cell surface area, stereovillar number, area of the stereovillar bundle, length of the long and short axis of the bundle, and the distance of the bundle to neural and abneural hair cell border) are shown overlaid and scaled both with respect to their maxi- mum value (Fig. 18a,c,e) and to the distance from the neural papillar border (Fig. 18b,d,f). These graphs demonstrate that, on average, parameters changed more in the neural half of the papilla and remained comparatively stable across the abneural half.

We also subjected the data to a cluster analysis (SPSS/PC+ statistics package) to determine whether there were objective criteria permitting the definition of distinct hair cell groups over the whole papillar area that might correspond to the previously described hair cell populations (e.g., tall and short). Analyzing all the data from the three positions $(20 \%, 50 \%$, and $80 \%$ from the base) together did not recognize clusters that were separated across the papilla; rather, it detected a difference between the apical versus the more basal positions.

Thus the data at the three positions were each subjected to a separate cluster analysis. (1). At $80 \%$ from the base, the analysis suggested only two clusters. However, one of them contained only the most neural hair cell; all 47 other cells were put into the second group. Unfortunately we could not analyze more hair cells within $25 \mu \mathrm{m}$ of the neural papilla edge at this position. The measure of group diversity showed only a very small and gradual decrease by increasing the number of groups from 2 to 10 , indicating no useful further subdivision of the 47 abneural hair cells into additional clusters. Thus according to the cluster analysis, all hair cells at least within the abneural $85 \%$ of the papilla belong to a homogenous population. (2). At $50 \%$ from the base, the cluster analysis 

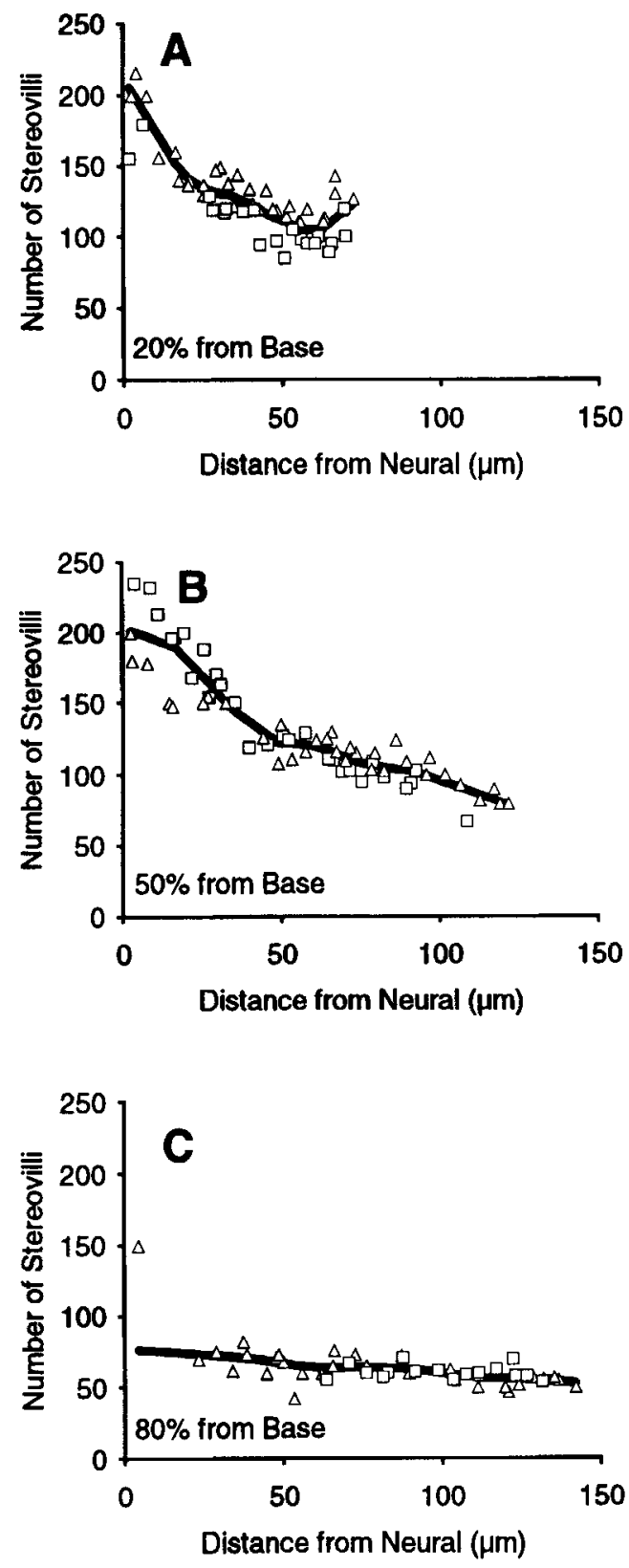

Fig. 9. Serinus canarius. The number of stereovilli as determined in two canary specimens for hair cells across the papilla at (A) $20 \%$, (B) $50 \%$, and (C) $80 \%$ from the basal end. Open squares and triangles code data from two different individuals. The heavy lines shows the smoothed, weighted average through the data. suggested a classification into three groups. Group I consisted of two very neural hair cells; the 17 group II hair cells were restricted to the neural $30 \%$ of the papilla; the group III contained the 42 more abneurally lying hair cells. (3). At $20 \%$ from the base, the analysis also suggested a clustering of hair cells into three groups. Group I contained eight hair cells, seven of which were within the neural $20 \%$ of the papilla (the other one was at the abneural edge). Hair cells of groups II and III were more abneural than those of group I but showed an almost complete overlap in their positions.

Considering the grouping by the cluster analysis with respect to the gradients shown in Figure 18, each of the eight suggested clusters consisted of a hair cell group that showed a unique set of characteristics. This was especially true if one compares neural or abneural clusters from different positions along the papilla. Thus, in our view, the hair cell groups suggested by this cluster analysis cannot be interpreted in terms of distinct groups of tall, intermediate, or short hair cells that can be recognized as equivalent along the entire papilla. Thus the present data emphasize strongly that it is not possible to define any sets of anatomical criteria to distinguish consistently between tall, intermediate, and short hair cells at any and all positions in the papilla. In addition, the constellation of features varies between species. In fact, in view of the complex trends shown in the different parameters, a good case can be made that every hair cell is unique and that all characteristics change gradually both across and along the papilla. Although we were not able to discriminate between hair cell types on morphological grounds, it may be convenient to retain the terms "tall," "short," and such to describe broad morphological categories, because the afferent and efferent innervation patterns might justify such a classification (Fischer et al., 1992).

\section{Comparison of anatomical differences among different species}

In order to keep the effects of different methodologies to a minimum, this comparison between data is mainly restricted to the results of SEM studies that employed similar methods to measure the different parameters.

The basilar papillae of canary and zebra finch were the shortest of all birds investigated to date. If we take into account that, due to the shrinkage of the tissue, the values 

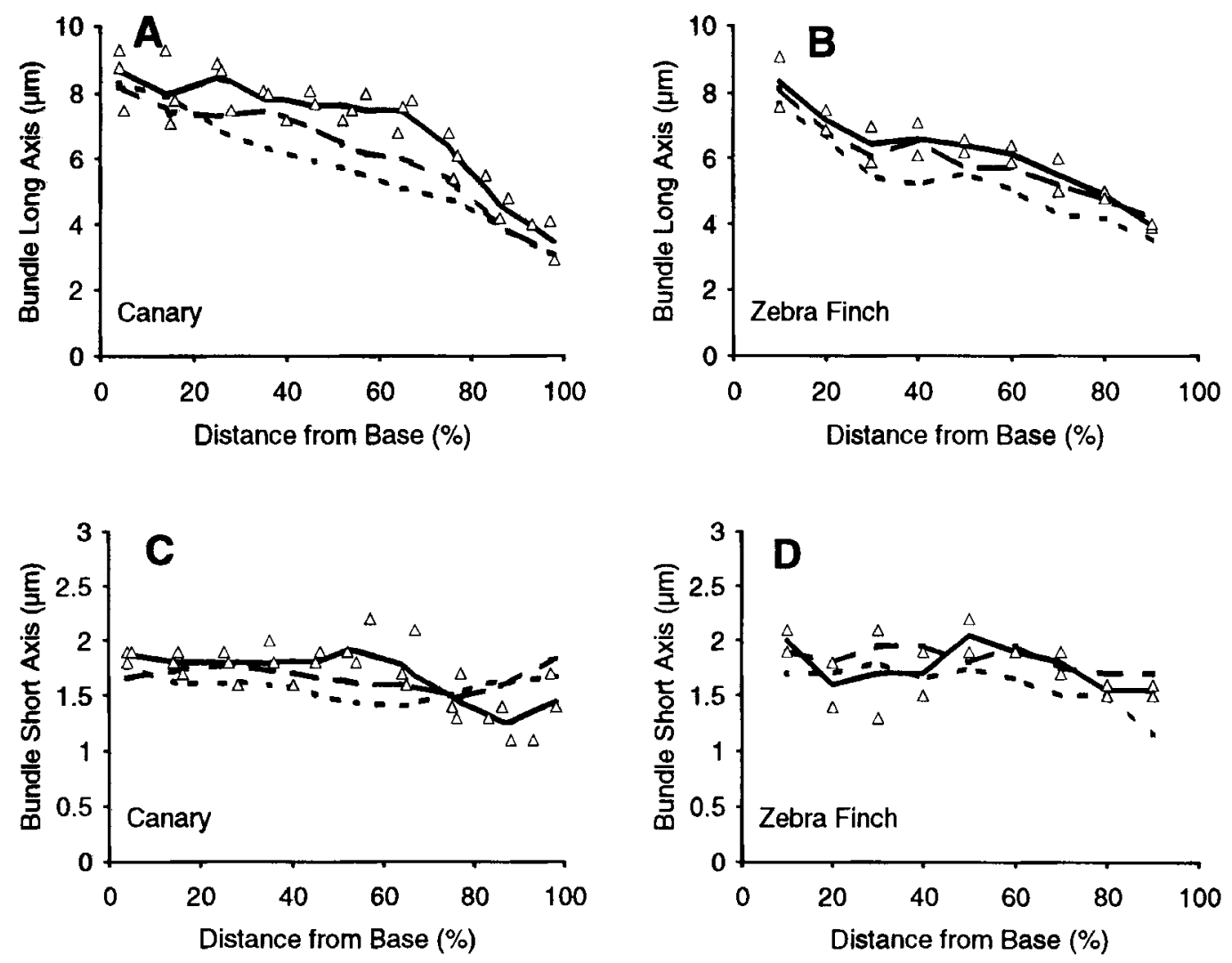

Fig. 10. Serinus canarius and Taeniopygia guttata. The length of the long axis $(\mathbf{A}, \mathbf{B})$ and the short axis of the stereovillar bundle $(\mathbf{C , D})$ as a function of the distance from the base for neural (continuous lines), middle (dashed lines), and abneural (dotted lines) hair cells. Open triangles show raw data obtained at the neural position. Averaged data are shown for $(A, C)$ three canary and $(B, D)$ two zebra finch specimens.

of papillar length in SEM specimens were smaller than those obtained with wholemounts or serial sections (a difference of 15$30 \%$; Fischer et al., '88; Gleich and Manley, '88) the basilar papilla of two other small songbird species, the pine sisken (Carduelis pinus) and the house sparrow (Passer domesticus, Smith, '81; '85) are of similar length to those of canary and zebra finch.

Among songbirds, the total number of hair cells in the canary $(3,000)$ was clearly lower than in the zebra finch $(3,570)$ and the starling $(5,830$; Gleich and Manley, '88). The only nonsongbird species with a low number of hair cells investigated to date is the shearwater, Puffinus puffinus, $(3,830$; Düring et al., '85). The hair cell number in the parakeet (Melopsittacus undulatus) is 5,370 (Manley et al., '93), whereas it is $\sim 10,000$ in the chicken and the pigeon (Düring et al., '85;
Gleich and Manley, '88; Goodley and Boord, '66; Rosenhall, '71; Tilney and Tilney, '86). The highest hair-cell numbers have been found in two owl species, 14,780 in Asio otus (Düring et al., '85), and 16,300 in Tyto alba (Fischer et al., '88).

The width of the avian basilar papilla increases gradually from the base toward a maximum and then decreases again toward the apex. However, the papillar dimensions vary considerably among species. In the chicken basilar papilla, published values for the width vary between $150 \mu \mathrm{m}$ (Tilney and Saunders, '83) and $300 \mu \mathrm{m}$ (Tanaka and Smith, '78). Published figures of chicken papillae (e.g., Cotanche, '87) and our own observations (e.g., Fig. 1 in Gleich and Manley, '88), however, indicate that the maximum width of the chicken papilla is $\sim 250 \mu \mathrm{m}$. Smith ('81) reported the maximum width of 

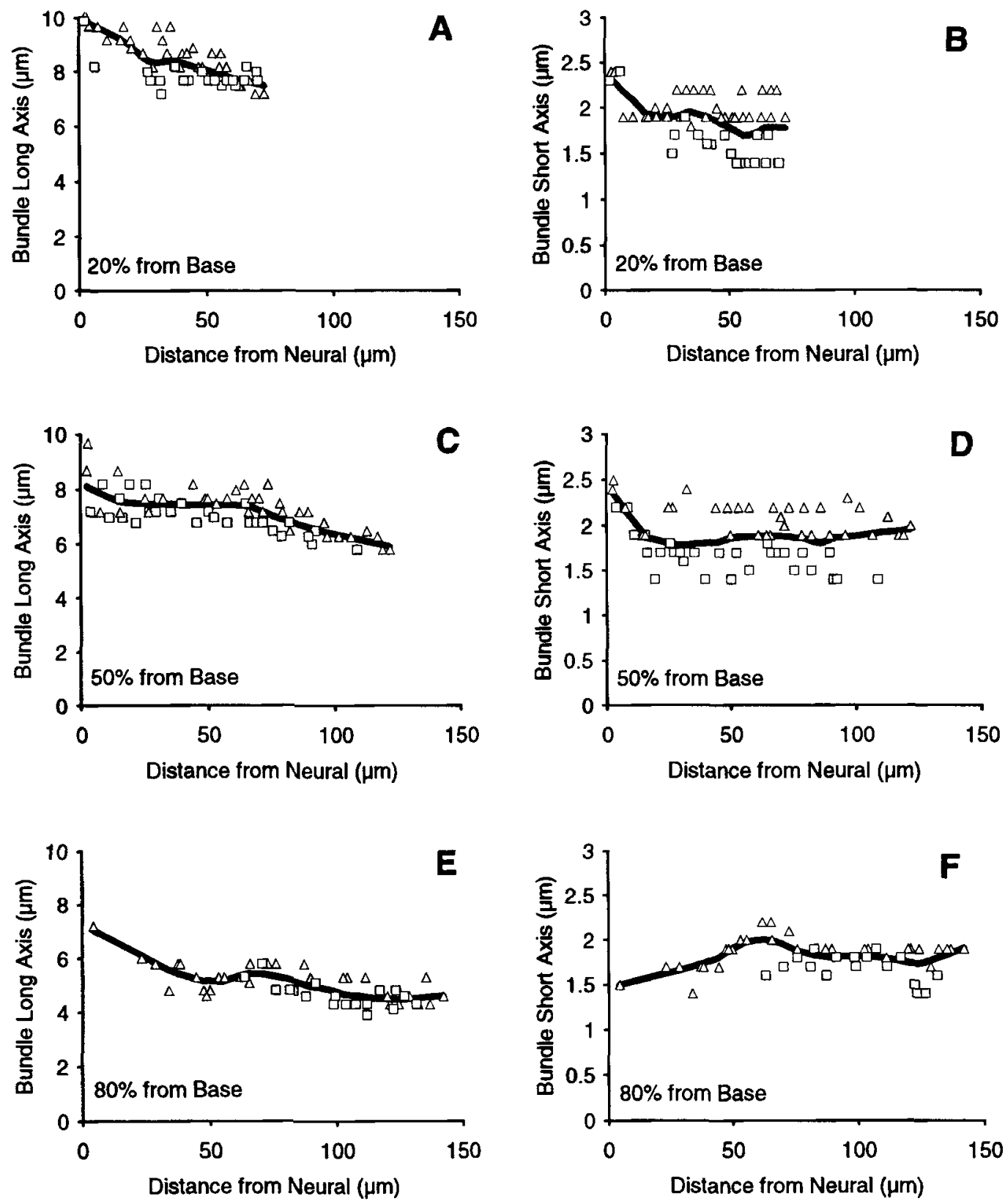

Fig. 11. Serinus canarius. The long axis $(\mathbf{A}, \mathbf{C}, \mathbf{E})$ and the short axis of the stereovillar bundle $(\mathbf{B}, \mathbf{D}, \mathbf{F})$ was determined in two canary specimens for hair cells across the papilla at $(A, B) 20 \%$, $(C, D) 50 \%$, and $(E, F) ~ 80 \%$ from the basal end. Open squares and triangles code data from two different individuals. The heavy lines show the smoothed, weighted averages through the data.

the basilar papilla of several bird species, but due to different methodology, they are difficult to compare with SEM material. The basilar papillae of song birds are narrower and thus have fewer hair cells across the papilla than in nonpasserine species. The canary basilar papilla described in the present work is the narrowest and has the small- 

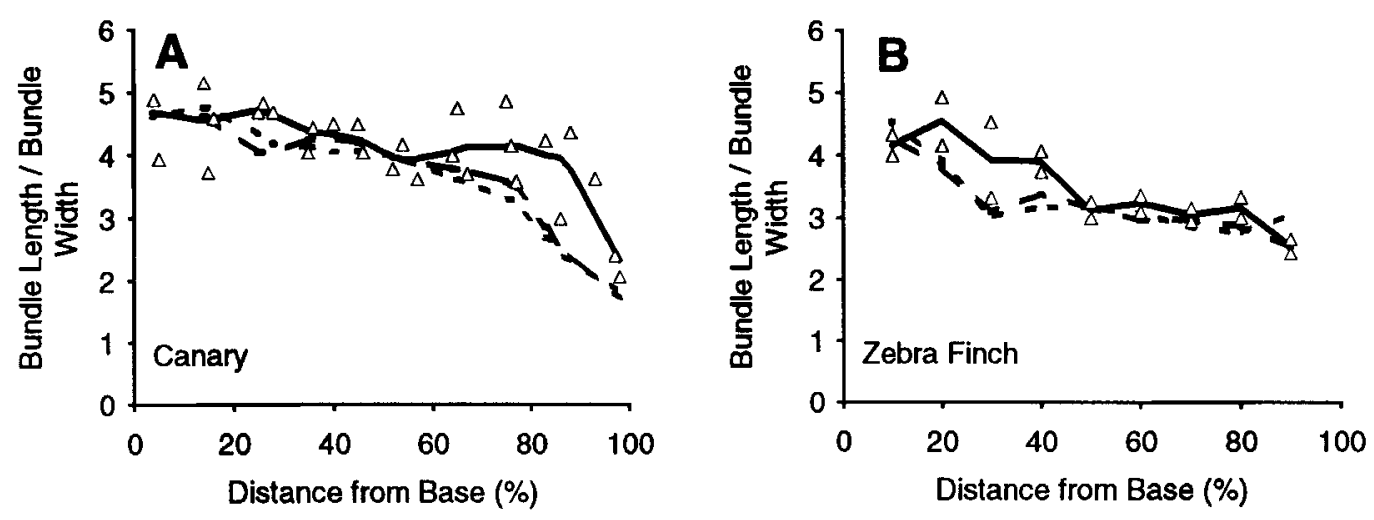

Fig. 12. Serinus canarius and Taeniopygia guttata. The shape of the stereovillar bundle characterized by the ratio of the length of the long and short bundle axes. The shape is shown as a function of the distance from the base for neural (continuous lines), middle (dashed lines), and abneural (dotted lines) hair cells. Open triangles show raw data obtained at the neural position. Averaged data are shown for (A) three canary and (B) two zebra finch specimens.

est number of hair cells across the epithelium, and in this respect is followed by the zebra finch and the starling.

The values obtained for the apical surface area of hair cells also depend on the species investigated. In the barn owl, the hair cell surface area was fairly constant across the papilla at any given location, but varied from $\sim 80 \mu \mathrm{m}^{2}$ in the basal half to $\sim 40 \mu \mathrm{m}^{2}$ in the apical half of the papilla (Fischer et al., '88). In all other bird species studied to date, there were not only changes along the papillar length, but also systematic differences between the surface area of neural and abneural hair cells. At the base and the apex of the papilla, the surface area of neural and abneural hair cells is similar and $\sim 30-40 \mu \mathrm{m}^{2}$ in the canary, zebra finch, starling, pigeon (Gleich and Manley, '88), and chicken (Tilney and Saunders, '83). The surface area of neural hair cells shows no or little systematic variation along the length of the papilla in the starling and only a slight decrease from the base to the apex in pigeon, chicken, canary, and zebra finch. The maximum apical surface area of abneural hair cells was speciesspecific with respect to the value reached at the respective locations along the papilla. In the pigeon, a distinct maximum of $120 \mu \mathrm{m}^{2}$ was reached in the middle of the papilla (Gleich and Manley, '88). In the chicken (Tilney and Saunders, '83) and the starling, the maximum of $80 \mu \mathrm{m}^{2}$ is also located in the middle of the papilla, being only a broad maximum in the starling (Gleich and Man- ley, '88). However, in the canary and zebra finch, in contrast to the other species, the maximum of abneural hair cell surface $(\sim 80$ $\mu \mathrm{m}^{2}$ ) was reached more apically, in the apical third of the papilla.

As the properties of the stereovillar bundle are expected to contribute to the micromechanics and the tuning mechanisms operating in the cochlea, they were characterized in some detail. The area of the hair cell apex occupied by the stereovillar bundle decreases gradually from the base toward the apex in all species except the barn owl, the decrease being most pronounced in the pigeon followed by canary, zebra finch, and starling. It is only in the canary and zebra finch that neural and abneural hair cells differ with respect to the area covered by the bundle. In these two species, neural hair cells in the middle between the base and the apex had systematically larger bundles than abneural hair cells.

In all species studied, the number of stereovilli decreases from 190-250 at the base to below 100 at the apex, but apical hair cells of canary and zebra finch had on average more stereovilli as compared to those of other species at this location. The most striking difference between the species studied to date, however, concerns the discrepancy in the number of stereovilli between neural and abneural hair cells. In the pigeon and starling, neural hair cells have slightly larger stereovillar numbers than abneural hair cells in the basal half of the papilla (Gleich and 

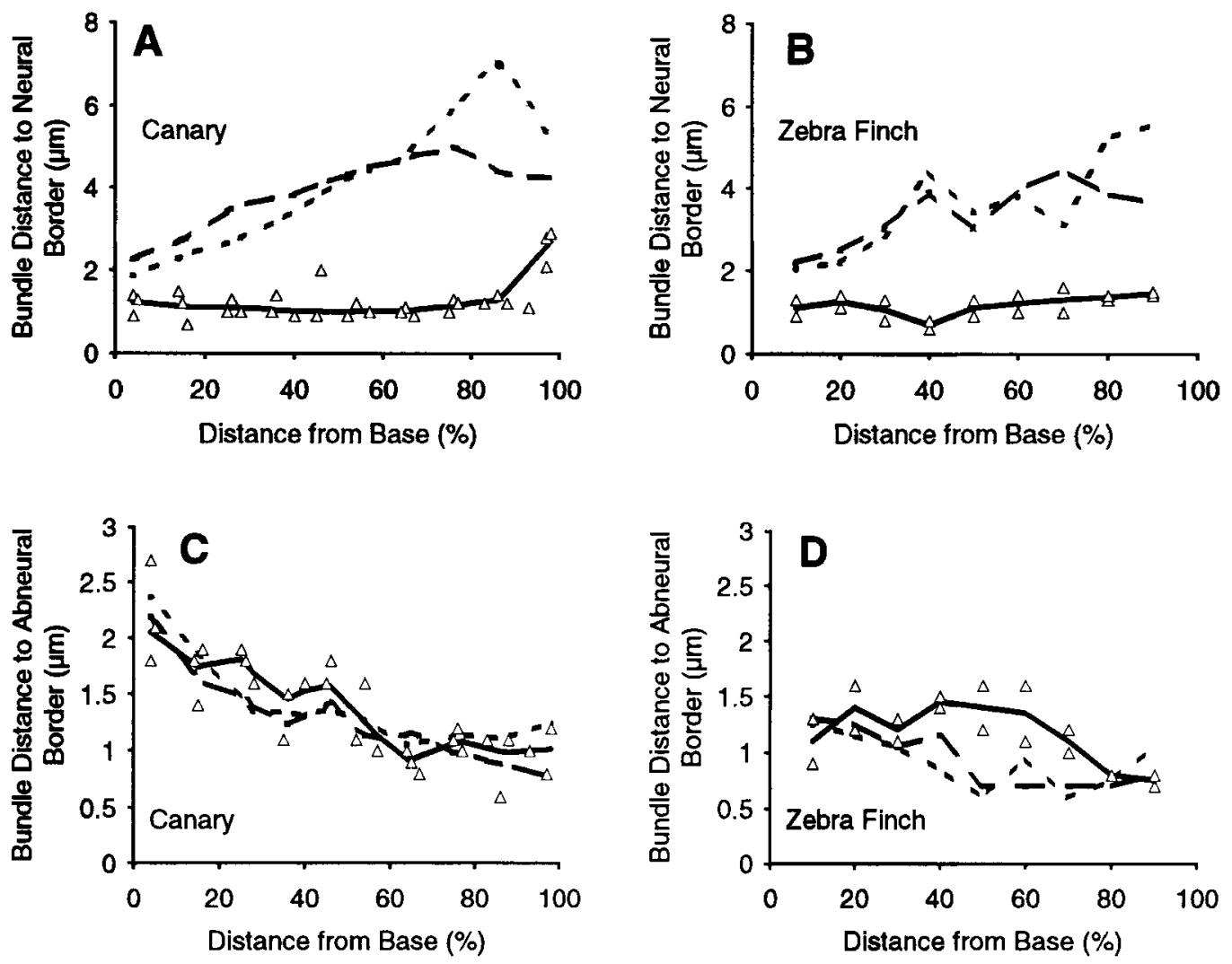

Fig. 13. Serinus canarius and Taeniopygia guttata. The distance of the stereovillar bundle to the (A,B) neural hair cell border and the distance of the stereovillar bundle to the abneural hair cell border (C,D) as a function of the distance from the base for neural (continuous lines), middle (dashed lines), and abneural (dotted lines) hair cells. Open triangles show raw data obtained at the neural position. Averaged data are shown for (A,C) three canary and (B,D) two zebra finch specimens.

Manley, '88). In the chicken (Tilney and Tilney, '88) and the barn owl (Fischer et al., '88), a comparatively small difference between neural and abneural hair cells exists and extends farther apically. In the budgerigar, there is a rather conspicuous difference in the stereovillar number of neural and abneural hair cells in the basal two-thirds of the papilla (Manley et al., '93). In the canary and zebra finch, however, the stereovillar number shows a very prominent difference between neural and abneural hair cells along almost the entire papilla.

In most species, the average stereovillar diameter is between 0.25 and $0.35 \mu \mathrm{m}$; only the barn owl has considerably thicker stereovilli. In the canary, zebra finch, budgerigar, and pigeon, there is no systematic variation of stereovilli diameter along the papilla, whereas diameters increase from the base to the apex in the starling and barn owl. In the chicken, Tilney and Saunders ('83) and Tilney et al. ('88) report that the stereovillar diameter was constant along the length of the papilla for neural hair cells, but increased from the base to the apex in abneural hair cells. The absolute values that they report are difficult to compare to our SEM measurements, because they were obtained using different techniques. Differences in stereovillar diameter of neural and abneural hair cells are thus more prominent in the canary, zebra finch, and budgerigar than in other birds. Although the observed differences in the canary and the zebra finch are small, it should be remembered that an increase in stereovil- 

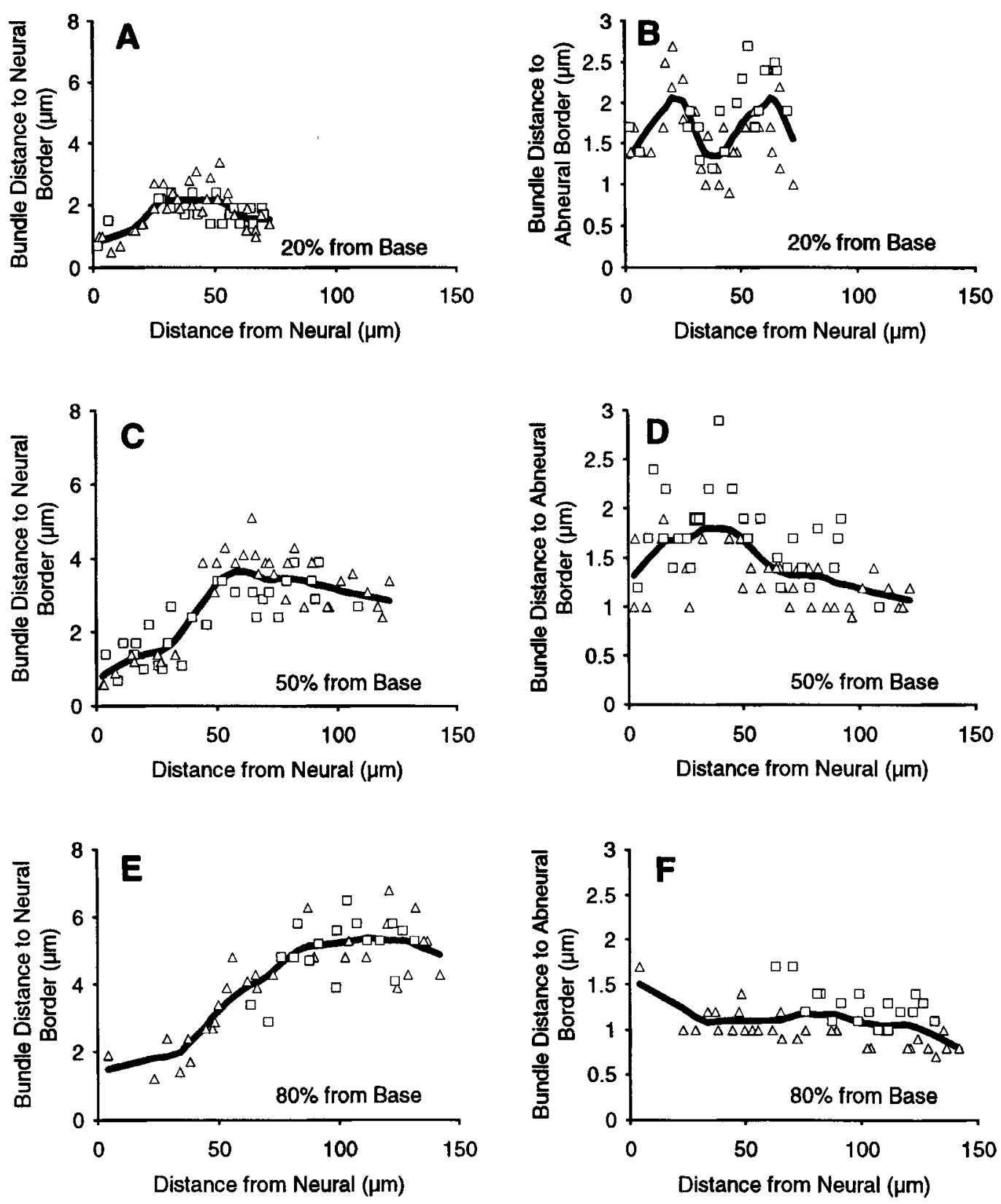

Fig. 14. Serinus canarius. The distance of the stereovillar bundle to the neural hair cell border $(\mathbf{A}, \mathbf{C}, \mathbf{E})$ and the distance to the abneural hair cell border $(\mathbf{B}, \mathbf{D}, \mathbf{F})$ were determined in two canary specimens for hair cells across the papilla at (A,B) $20 \%$, (C,D) $50 \%$, and (E,F) $80 \%$ from the basal end. Open squares and triangles code data from two different individuals. The heavy line shows the smoothed, weighted average through the data. 


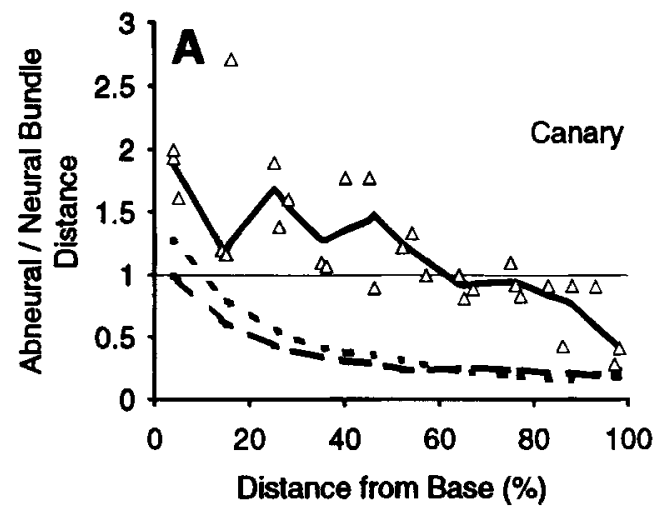

Fig. 15. Serinus canarius and Taeniopygia guttata. The location of the stereovillar bundle on the hair cell characterized as the ratio of the distance of the bundle to the abneural and neural hair cell border. Symmetrically placed bundles have values of 1 . Bundles located nearer the neural side of the hair cell (potential lenticular hair cells) are characterized by values above 1 , whereas values below indicate that bundles are located nearer the abneu-

lar diameter from $0.25 \mu \mathrm{m}$ to $0.28 \mu \mathrm{m}$ means a potential increase of $20 \%$ in actin content and thus bundle stiffness.

The shape of stereovillar bundles changes systematically over the basilar papilla. The bundle long axis decreases gradually from $7-9 \mu \mathrm{m}$ at the base to $\sim 3 \mu \mathrm{m}$ at the apex in all species with the exception of the barn owl. In the canary, zebra finch, and barn owl, the bundle long axis of neural hair cells, because of the larger number of stereovilli, tends to be longer than in abneural hair cells. At the apex, the bundle's long axis in barn owls is about twice that of other birds. The short axis of the bundle shows little variation along the papilla in the canary and zebra finch, an increase in the starling and barn owl and a decrease in the pigeon (Fischer et al., '88; Gleich and Manley, '88). A small, systematic variation of the bundle short axis was verified for the canary by systematically plotting this parameter across the papilla (Fig. 11). In general, the bundle shape factors in all species investigated show that bundles are more elongated at the base of the cochlea than at the apex. However, the degree of variation of bundle shape along and across the cochlea is unique for each of the species investigated.

Of the parameters used to identify lenticular hair cells (Smith, '85; Smith et al., '85), we were only able to determine the distance between the edge of the hair bundle and the abneural and neural hair cell border for rep-

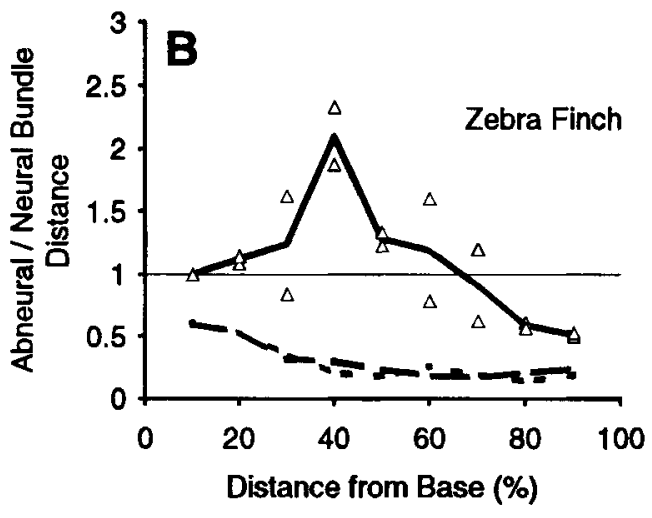

ral side of the hair cell. The location of the bundle on the hair cell surface is shown as a function of the distance from the base for neural (continuous line), middle (dashed line), and abneural (dotted line) hair cells. Data are from (A) three canary and (B) two zebra finch specimens. Open triangles show raw data obtained at the neural position.

resentative cells. As we could not characterize the cross-sectional shape of the hair cells or the cuticular plates in our SEM specimens, not all of the cells with bundles lying excentrically on the neural side of the hair cell are necessarily lenticular hair cells. However, all hair cells with abneurally located bundles are, per definition, not lenticular. Of course, as the location of the bundle on the hair cell surface varied gradually with the cell's position on the papilla (Figs. 15, 16), there might be a gradual transition between lenticular and other hair cell types.

The pattern of hair cell orientation on the basilar papilla of the canary and the zebra finch is similar to that in other birds investigated, except that the maximum rotation of the bundles toward the apex is smaller in the canary and zebra finch $\left(30-40^{\circ}\right)$ than in the pigeon, starling, barn owl and chicken (70$90^{\circ}$; Brix, '91; Fischer et al., '88; Gleich and Manley, '88; Tilney et al., '87). In addition, the maximum bundle rotation in the canary and zebra finch was restricted to the most apical tip of the papilla, whereas it is found in the apical third of the papilla in the starling and pigeon.

\section{Correlation of anatomical features with auditory performance}

The above discussion shows that a number of morphological gradients of the canary and zebra finch cochlea differ from those in other 

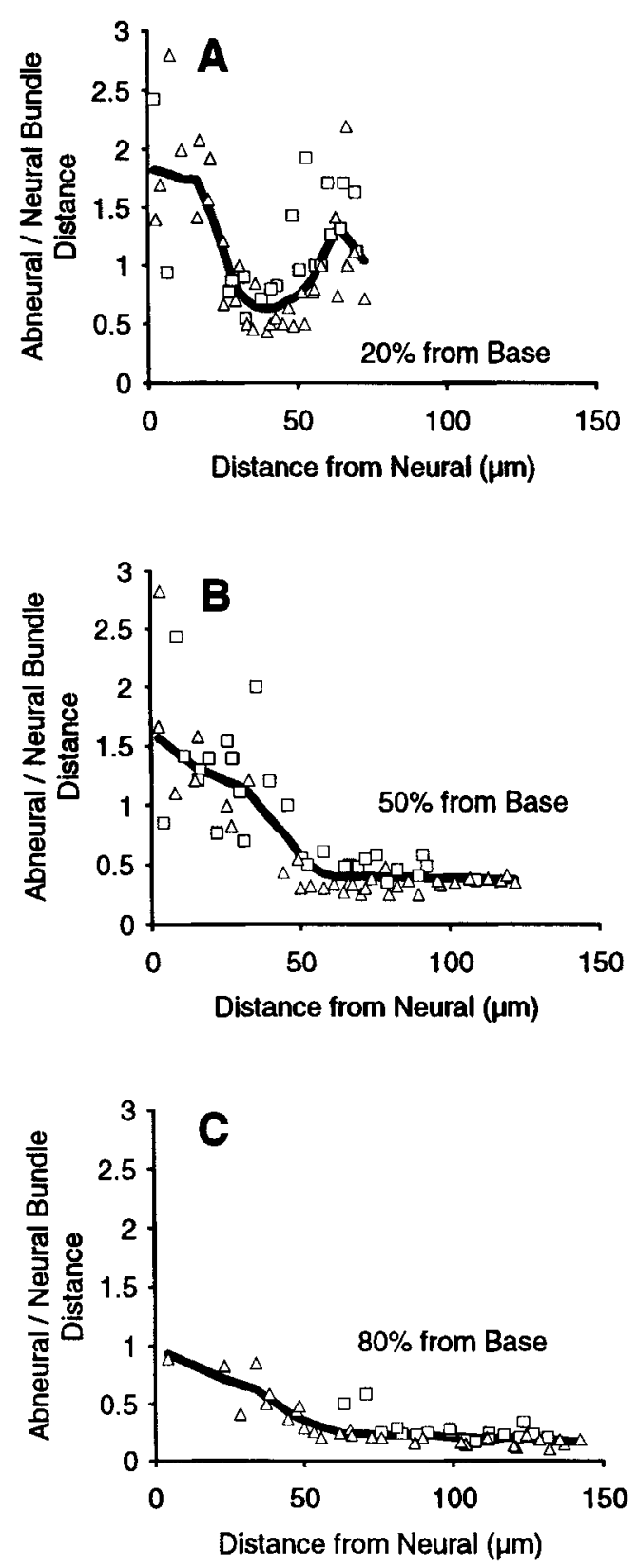

Fig. 16. Serinus canarius. The location of the stereovillar bundle on the hair cell were determined in two canary specimens for hair cells across the papilla at (A) $20 \%$, (B) $50 \%$, and (C) $80 \%$ from the basal end. Open squares and triangles code data from two different individuals. The heavy line shows the smoothed weighted average through the data. avian species. A number of these differences indicate that typical "basal" (ie, high frequency) features are more pronounced than typical "apical" (i.e., low frequency) features in the canary and zebra finch:

1. The maximum width and the maximum number of hair cells across the papilla are smaller than in other birds (Fig. 2).

2. The hair cell surface area of abneurally lying hair cells reached its maximum further apically than in other species (Fig. 4 and discussion above).

3. The discrepancy in the number of stereovilli of neural and abneural hair cells is much more pronounced in the canary and zebra finch than in other species, and apical hair cells have rather high numbers of stereovilli (Figs. 8, 9).

4. The shape of stereovillar bundles on apical hair cells is more elangated than in other species (Fig. 12).

5. The maximum rotation of the stereovillar bundles is reached at the extreme apical end and is small compared to other species (Fig. 17 and discussion above).

Thus, although no frequency map or other physiological data are available for the canary and zebra finch cochlea, the emphasis of features typical of the cochlear base indicates improved high- and less-developed, low-frequency hearing. Behavioral data at least partly bear out this expection. Surveying the behavioral audiograms for 23 different species of passerine and nonpasserine birds (Dooling, '92), canaries and zebra finches have among the poorest sensitivity at frequencies below two $\mathrm{kHz}$. The threshold at 0.5 $\mathrm{kHz}$ for the average bird ( 23 species) is $\sim 27$ dB SPL, whereas for canaries and zebra finches it is 46 and $51 \mathrm{~dB} \mathrm{SPL}$, respectivelyalmost two standard deviations above the mean for the 23 species.

In terms of high-frequency hearing, however, the canary and zebra finch are in fact similar to other passerines that have been tested. For the average passerine, the best frequency of hearing is at $2.9 \mathrm{kHz}$, where thresholds on average are $\sim 5 \mathrm{~dB}$ SPL. At higher frequencies, sensitivity declines at the rate of $\sim 35 \mathrm{~dB}$ per octave, to a threshold of $60 \mathrm{~dB}$ SPL at $9.7 \mathrm{kHz}$. Published audiograms for canaries (Okanoya and Dooling, '85) and zebra finches (Okanoya and Dooling, '87; Hashino and Okanoya, '89) show that their best frequency of hearing is slightly higher $(3.3 \mathrm{kHz})$ with a best threshold near $12 \mathrm{~dB}$ SPL. The high-frequency $60 \mathrm{~dB}$-threshold is 

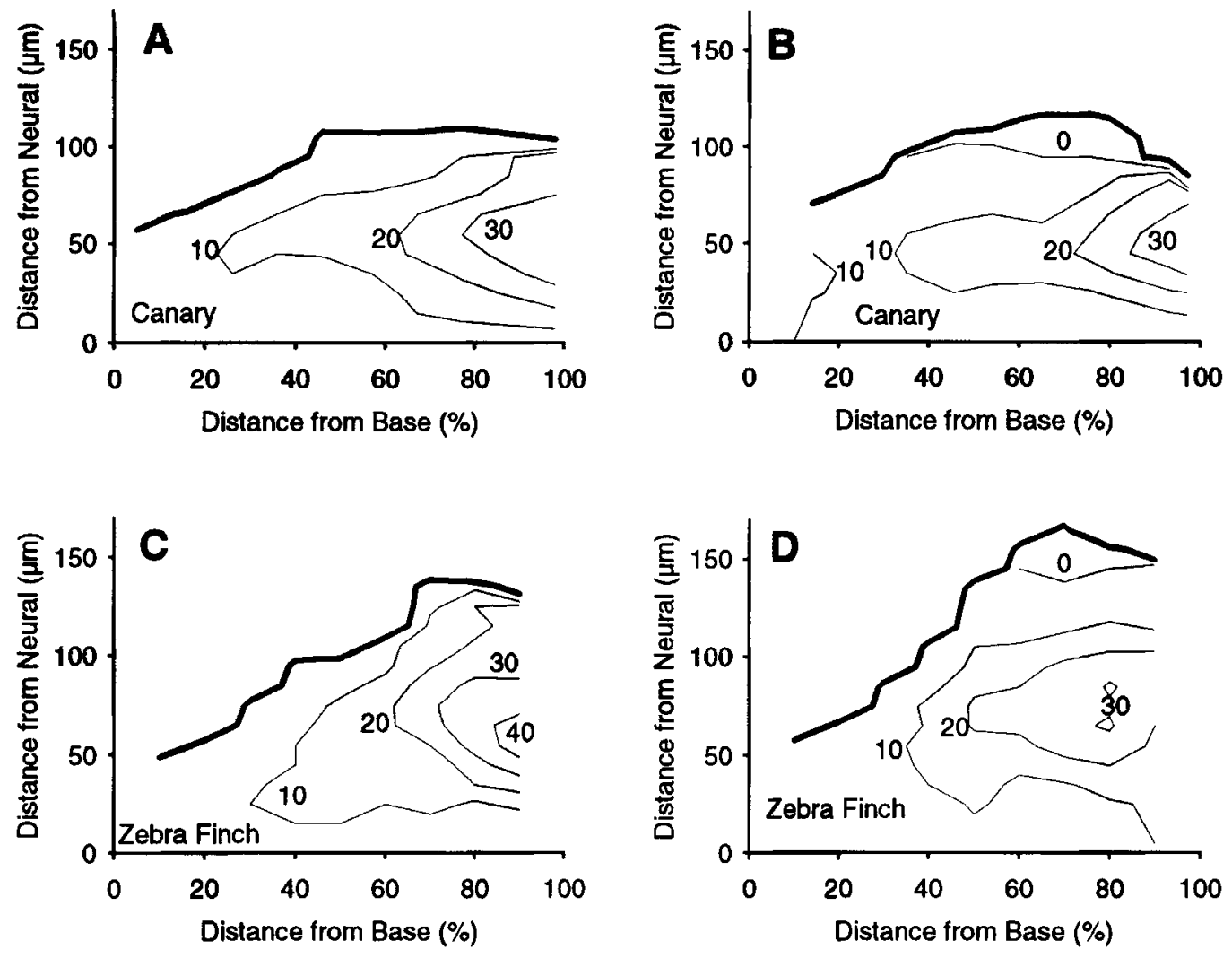

Fig. 17. Serinus canarius and Taeniopygia guttata. The pattern of hair-cell orientation on the surface of the basilar papilla from four specimens (A-D). The neural edge of the papilla is converted to a straight line and represented by the $x$-axes. The heavy lines indicate the abneural edge of the papillae. Thin lines are the isoorientation contours representing different angles of hair cell rotation towards the apex, as indicated by the num-

reached at 9.7 and $8.7 \mathrm{kHz}$ in the canary and zebra finch, respectively, and is thus similar to the average of other passerines. Thus we conclude that the "basal" features of the cochleae of these species are not correlated with improved high-frequency hearing, but with reduced low-frequency sensitivity.

We also studied correlations between a variety of audiogram parameters (threshold at $0.5 \mathrm{kHz}$, high-frequency cutoff at $60 \mathrm{~dB} \mathrm{SPL}$, best frequency, best threshold, and bandwidth $40 \mathrm{~dB}$ above threshold) and the grossanatomical parameters (length of the papilla, number of hair cells, maximum width of the papilla, and the maximum number of hair cells across the papilla) for the six avian species where both data sets are available (canary, zebra finch, starling, budgerigar, pi-

bers close to the line. An angle of $0^{\circ}$ means that the long axes of the stereovillar bundles are parallel to the neural edge of the papilla, higher values indicate that the hair cells are rotated toward the apex and indicate the angle between the neural edge of the papilla and the long axis of the stereovillar bundle. Two examples from $(A, B)$ canary and $(C, D)$ zebra finch are shown.

geon, and barn owl). The audiogram data were obtained according to Dooling ('92) from several reviews (Dooling, '80, '82; Fay, '88), whereas anatomical data were taken from several additional studies (Fischer et al., '88; Gleich et al., '88; Manley et al., '93). We found inverse relationships between the audiogram threshold at $0.5 \mathrm{kHz}$ and the three parameters length of the papilla (number of species, $\mathrm{n}=6, \mathrm{r}=-0.84, P<0.05)$, total number of hair cells (number of species, $\mathrm{n}=6, \mathrm{r}=-0.91, P<0.05$ ), and maximum papillar width (number of species, $n=6$, $\mathrm{r}=-0.82, P<0.05$ ). The best threshold of the audiogram is inversely related to the length of the papilla (number of species, $\mathrm{n}=6, \mathrm{r}=-0.97, P<0.05$ ) and the total number of hair cells (number of species, 

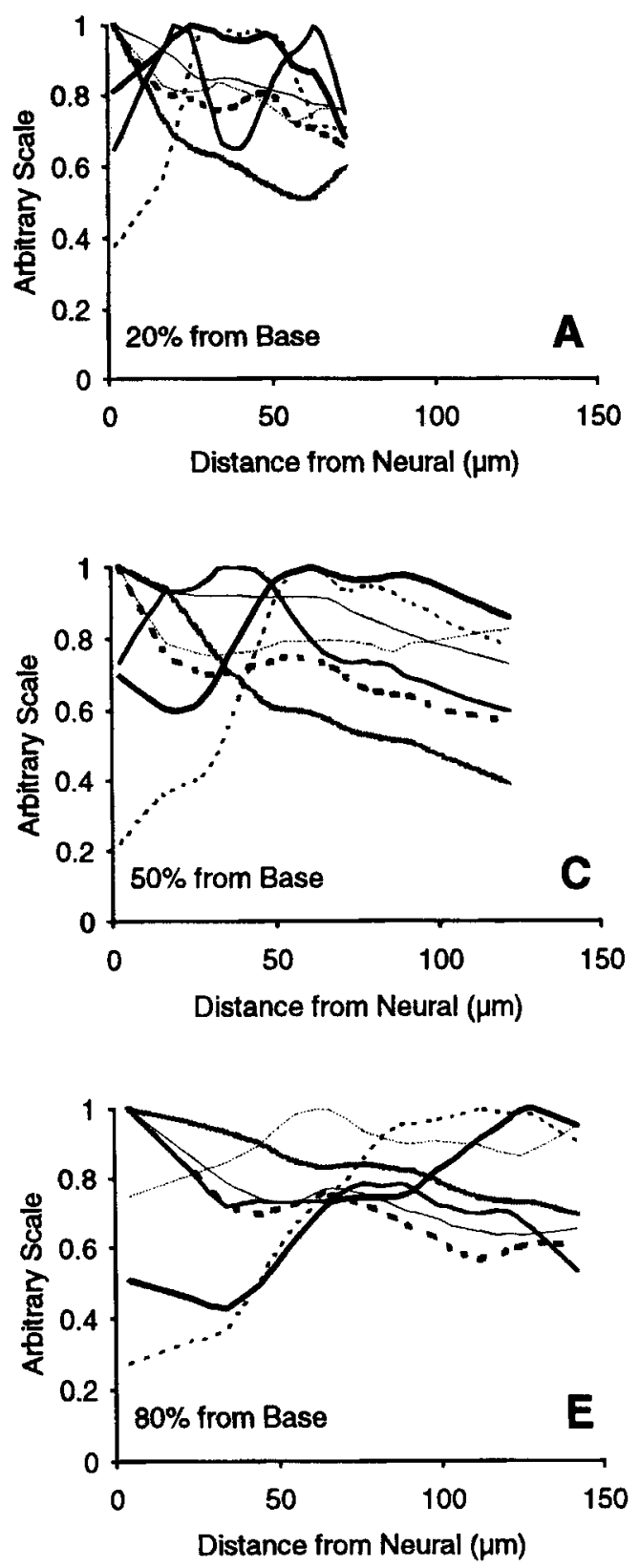

Fig. 18. Serinus canarius. The gradients of all directly measured parameters across the papilla, normalized both with respect to their maximum $(\mathbf{A}, \mathbf{C}, \mathbf{E})$ and to the width of the papilla $(\mathbf{B}, \mathbf{D}, \mathbf{F})$ and plotted together for the positions $20 \%(\mathrm{~A}, \mathrm{~B}), 50 \%(\mathrm{C}, \mathrm{D})$, and $80 \%(\mathrm{E}, \mathrm{F})$ from the basal end. In the graphs, different line types code for the following measurements: number of stereovilli $=$ thick grey line; hair-cell surface area = thick black line; area occupied by stereovillar bundle $=$ thick dotted line;
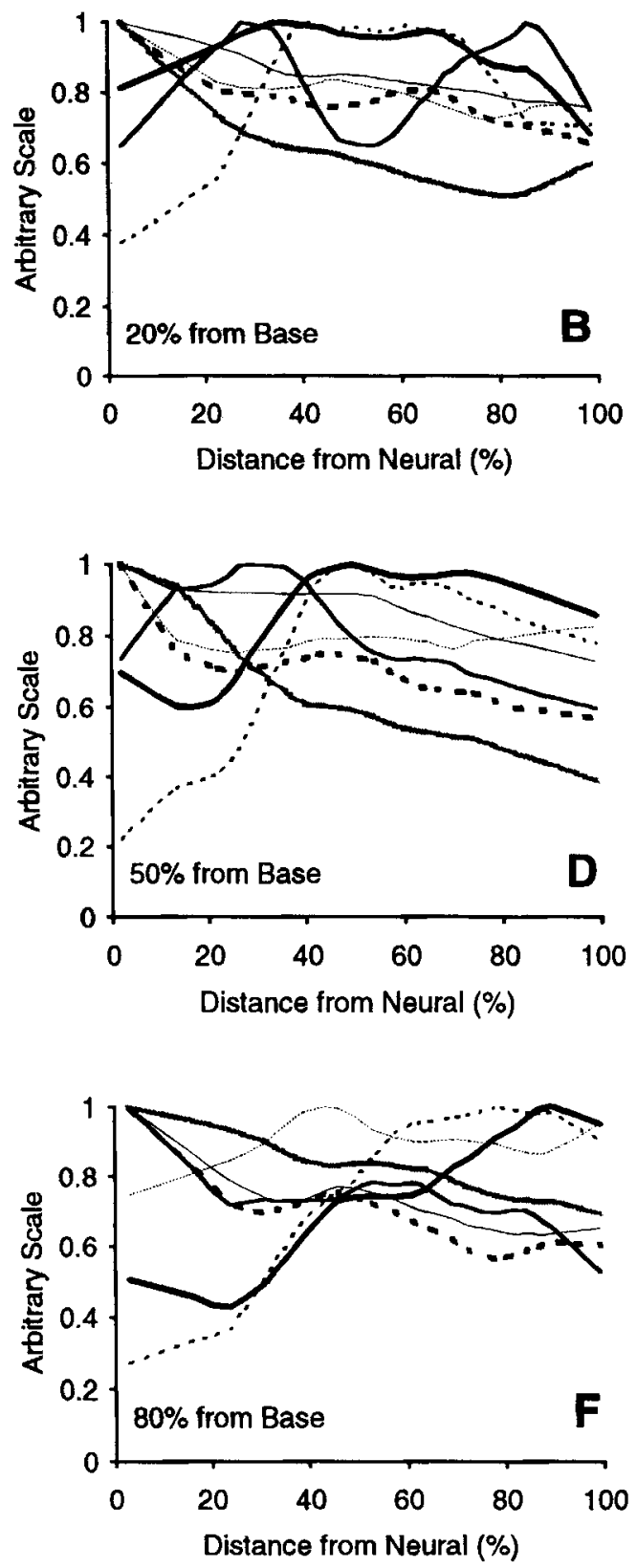

bundle distance to abneural hair-cell border $=$ intermediate black line; bundle distance to neural hair-cell border = intermediate dotted line; length of bundle long axis =thin black line; length of bundle short axis = thin dotted line. These graphs do not indicate clear borders that discriminate clearly between hair cell types. However, most of the parameters investigated show more prominent changes in the neural half of the papilla as compared to the abneural half. 
$\mathrm{n}=6, \mathrm{r}=-0.89, P<0.05$ ), whereas the bandwidth of the audiogram (40 $\mathrm{dB}$ above the best threshold) shows a positive relation to the maximum width of the papilla (number of species, $\mathrm{n}=6, \mathrm{r}=0.82, P<0.05$ ) and to the total number of hair cells (number of species, $\mathrm{n}=6, \mathrm{r}=0.84, P<0.05$ ).

Masking data and anatomical data that have been collected in the same laboratories using the same procedures were available for the canary, zebra finch, starling, and budgerigar (Okanoya and Dooling, '87; Langemann et al., pers. comm.). Comparing the critical ratios at the frequency of best hearing for each of these four species with the anatomical data revealed trends for an inverse relationship between the size of the critical ratio and the total number of hair cells on the papilla (number of species, $\mathrm{n}=4, \mathrm{r}=-0.84$, $0.1<P<0.05$ ), the maximum width of the papilla (number of species, $n=4, r=-0.95$, $P<0.05$ ), and the maximum number of hair cells across the papilla (number of species, $\mathrm{n}=4, \mathrm{r}=-0.90,0.1<P<0.05$ ). Canaries have unusually large critical ratios $(32 \mathrm{~dB})$ in their region of best hearing, followed by zebra finches $(27 \mathrm{~dB})$, starlings $(24 \mathrm{~dB})$, and budgerigars $(19 \mathrm{~dB})$.

The observations described above indicate that the growing comparative data base concerning the performance and anatomy of the hearing organs of different avian species is providing a new basis for elucidating the relationships between structure and function. With regard to the species described in the present study, the short and narrow papillae of canary and zebra finch correlate with comparatively high thresholds at low frequencies and with a low spectral resolution at the frequency of maximum sensitivity. Highfrequency thresholds, however, are similar to those of other passerines.

\section{ACKNOWLEDGMENTS}

This study was supported by the Deutsche Forschungsgemeinschaft within the program of Project 2 of the SFB 204 ("Gehör"). Undergraduate students C. Maucher, T. Schmidt, and $\mathrm{K}$. Weißbacher helped in analyzing the zebra-finch data during an advanced research course. K. Bielenberg helped with the analysis of the canary data. C. Köppl performed the cluster analysis on the canary data. F.P. Fischer and G. Schwabedissen provided support with the SEM. G. Schwabedissen helped with photography. F.P. Fischer and C. Köppl improved the manuscript by critical comments on an earlier version. Un- published critical ratio data from the starling are from U. Langemann, G.M. Klump, and R.J. Dooling (1993). Critical bands and critical ratio bandwidth in the European starling (Sturnus vulgaris) (in prep).

\section{LITERATURE CITED}

Brix, J. (1991) Anatomie und elektro-mechanische Eigenschaften der Haarzellen der Papilla basilaris des Hühnerkükens, Gallus gallus domesticus. Ph.D. Dissertation, Fakultät für Chemie, Biologie und Geowissenschaften der Technischen Universität München.

Cleveland, W.S. (1979) Robust locally weighted regression and smoothing scatterplots. J. Am. Stat. Ass. 74:829-836.

Cotanche, D.A. (1987) Development of hair cell stereocilia in the avian cochlea. Hearing Res. 28:35-44.

Cotanche, D.A., and J.T. Corwin (1991) Stereociliary bundles reorient during hair cell development and regeneration in the chick cochlea. Hearing Res. 52:379402 .

Dooling, R.J. (1980) Behavior and psychophysics of hearing in birds. In: A.N. Popper and R.R. Fay (eds): Comparative Studies of Hearing in Vertebrates. New York: Springer-Verlag, pp. 261-288.

Dooling, R.J. (1982) Auditory perception in birds. In: D. Kroodsma and E. Miller (eds): Acoustic Communication in Birds, Vol. 1. New York: Academic Press, pp. 95-130.

Dooling, R.J. (1992) Hearing in birds. In: D.B. Webster, R.R. Fay and A.N. Popper (eds): The Evolutionary Biology of Hearing. New York: Springer-Verlag, pp. 545-559.

Düring, M. von, K.H. Andres, and K. Simon (1985) The comparative anatomy of the basilar papillae in birds. Fortschr. Zool. 30:681-685.

Fay, R.R. (1988) Hearing in Vertebrates: A Psychophysics Databook. Winnetka, IL: Hill-Fay.

Firbas, W., and G. Müller (1983) The efferent innervation of the avian cochlea. Hearing Res. 10:109-116.

Fischer, F.P. (1992) Quantitative analysis of the innervation of the chicken basilar papilla. Hearing Res. 61:167178.

Fischer, F.P., C. Köppl, and G.A. Manley (1988) The basilar papilla of the barn owl Tyto alba: A quantitative morphological SEM analysis. Hearing Res. 34:87-102.

Fischer, F.P., C. Miltz, I. Singer, and G.A. Manley (1992) Morphological gradients in the starling basilar papilla. J. Morphol. 213:225-240.

Fuchs, P.A., T. Nagai, and M.G. Evans (1988) Electrical tuning in hair cells isolated from the chick cochlea. J. Neurosci. 8:2460-2467.

Gleich, O. (1989) Auditory primary afferents in the starling: Correlation of function and morphology. Hearing Res. 37:255-268.

Gleich, O., and G.A. Manley (1988) Quantitative morphological analysis of the sensory epithelium of the starling and pigeon basilar papilla. Hearing Res. 34:69-85.

Goodley, L.B., and R.L. Boord (1966) Quantitative analysis of the hair cells of the auditory papilla of the pigeon. Amer. Zool. 6:542.

Hashino, E., and K. Okanoya (1989) Auditory sensitivity in the zebra finch (Poephila guttata castanotis). J. Acoust. Soc. Jpn. 10:51-52.

Hudspeth, A.J., and R. Jacobs (1979) Stereocilia mediate transduction in vertebrate hair cells. Proc. Nat. Acad. Sci. USA 76:1506-1509. 
Köppl, C., O. Gleich, and G.A. Manley (1993) An auditory fovea in the barn-owl cochlea. J. Comp. Physiol. [A] 171:695-704

Kreithen, M.L., and D.B. Quine (1979) Infrasound detection by the homing pigeon: A behavioral audiogram. J. Comp. Physiol. 129:1-4.

Manley, G.A. (1990) Peripheral Hearing Mechanisms in Reptiles and Birds. Berlin: Springer Verlag.

Manley, G.A., and O. Gleich (1992) Evolution and specialization of function in the avian auditory periphery. In D.B. Webster, R.R. Fay, and A.N. Popper (eds): The Evolutionary Biology of Hearing. New York: Springer Verlag, pp. 561-580.

Manley, G.A., J. Brix, and A. Kaiser (1987) Developmental stability of the tonotopic organization of the chick's basilar papilla. Science 237:655-656.

Manley, G.A., C. Haeseler, and J. Brix (1991) Innervation pattern and spontaneous activity of afferent fibres to the lagenar macula and apical basilar papilla of the chick's cochlea. Hearing Res. 56:211-226.

Manley, G.A., G. Schwabedissen, and O. Gleich (1993) Morphology of the basilar papilla of the budgerigar Melopsittacus undulatus. J. Morphol. 281:153-165.

Manley, G.A., O. Gleich, H.-J. Leppelsack, and H. Oeckinghaus (1985) Activity patterns of cochlear ganglion neurones in the starling. J. Comp. Physiol. [A] 157:161181.

Manley, G.A., O. Gleich, A. Kaiser, and J. Brix (1989) Functional differentiation of sensory cells in the avian auditory periphery. J. Comp. Physiol. [A] 164:289-296.

Okanoya, K., and R.J. Dooling (1985) Colony differences in auditory thresholds in the canary (Serinus $\mathrm{ca}$ narius). J. Acoust. Soc. Am. 78:1170-1176.

Okanoya, K., and R.J. Dooling (1987) Hearing in passerine and psittacine birds: A comparative study of masked and absolute auditory threshold. J. Comp. Psychol. 101:7-15

Rosenhall, U. (1971) Morphological patterns of the organ of Corti in birds. Archiv klin. exp. Ohr-Nas, u. Kehlk. Heilk. 200:42-63.

Ryals, B.M., and E.W. Westbrook (1988) Ganglion cell and hair cell loss in Coturnix quail associated with aging. Hearing Res. 36:1-8.
Ryals, B.M., and E.W. Westbrook (1990) Hair cell regeneration in senescent quail. Hearing Res. 50:87-96.

Sachs, M.B., E.D. Young, and R.H. Lewis (1974) Discharge patterns of single fibers in the pigeon auditory nerve. Brain Res. 70:431-447.

Schermuly, L., and R. Klinke (1990) Origin of infrasound sensitive neurones in the papilla basilaris of the pigeon: An HRP study. Hearing Res. 48:69-78.

Smith, C.A. (1981) Recent advances in structural correlates of auditory receptors. In D. Ottoson (ed): Progress in Sensory Physiology, Vol 2. New York: SpringerVerlag, pp. 135-187.

Smith, C.A. (1985) Inner ear. In: A.S. King and J. McLeland $J$ (eds): Form and Function in Birds, Vol. 3 London, Academic Press, pp. 273-310.

Smith, C.A., M. Konishi, and N. Schuff (1985) Structure of the barn owl's (Tyto alba) inner ear. Hearing Res. 17:237-247.

Takasaka, T., and C.A. Smith (1971) The structure and innervation of the pigeon's basilar papilla. J. Ultrastruct. Res. 35:20-65

Tanaka, K., and C.A. Smith (1978) Structure of the chicken's inner ear: SEM and TEM study. Am. J. Anat 153:251-271.

Tilney, L.G., and J.C. Saunders (1983) Actin filaments, stereocilia, and hair cells of the bird cochlea. I. length number, width and distribution of stereocilia of each hair cell are related to the position of the hair cell on the cochlea. J. Cell Biol. 96:807-821.

Tilney, L.G., and M.S. Tilney (1986) Functional organization of the cytoskeleton. Hearing Res. 22:55-77.

Tilney, L.G., and M.S. Tilney (1988) The actin filament content of hair cells of the bird cochlea is nearly constant even though the length, width and number of stereocilia vary depending on the hair cell location. J. Cell Biol. 107:2563-2574.

Tilney, M.S., L.G. Tilney, and D.J. DeRosier (1987) The distribution of hair cell bundle lengths and orientations suggests an unexpected pattern of hair cell stimulation in the chick cochlea. Hearing Res. 25:141-151.

Tilney, L.G., M.S. Tilney, and D.A. Cotanche (1988) New observations on the stereocilia of hair cells of the chick cochlea. Hearing Res. 37:71-82. 